Document downloaded from:

http://hdl.handle.net/10251/104009

This paper must be cited as:

Serrano, J.; Tiseira, AO.; García-Cuevas González, LM.; Inhestern, LB.; Tartoussi, H. (2017). Radial turbine performance measurement under extreme off-design Conditions. Energy. 125:72-84. doi:10.1016/j.energy.2017.02.118

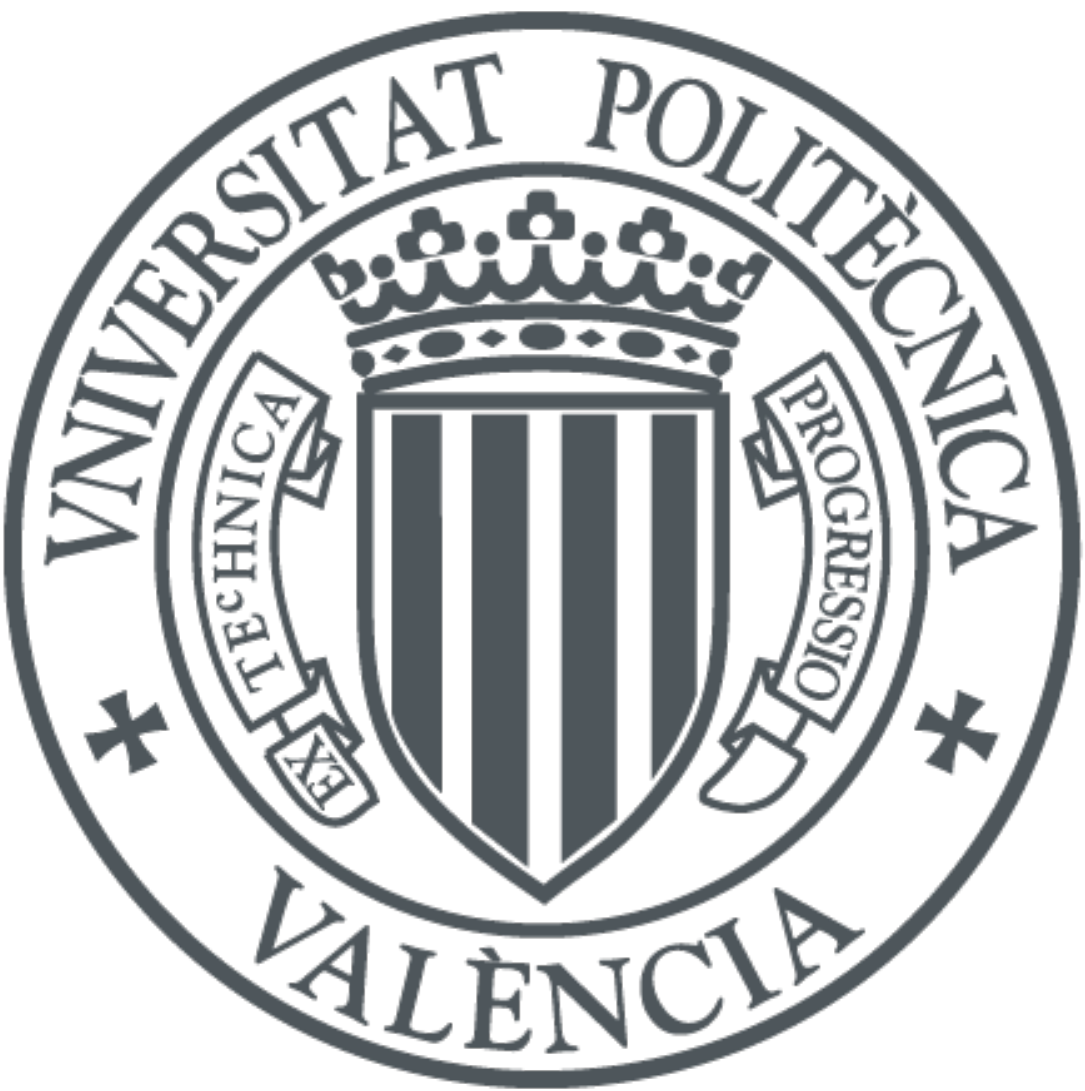

The final publication is available at

http://doi.org/10.1016/j.energy.2017.02.118

Copyright Elsevier

Additional Information 


\title{
Radial Turbine Performance Measurement Under Extreme Off-Design Conditions
}

\author{
José Ramón Serrano ${ }^{a}$, Andrés Tiseira ${ }^{a}$, Luis Miguel García-Cuevas ${ }^{a, *}$, Lukas Benjamin Inhestern ${ }^{a}$, Hadi \\ Tartoussi $^{\mathrm{b}}$ \\ ${ }^{a}$ CMT-Motores Térmicos, Universitat Politècnica de València, Valencia 46022, Spain. \\ ${ }^{b}$ Renault S.A.S., Powertrain Division, Centre Technique de Lardy, France
}

\begin{abstract}
During automotive urban driving conditions and future homologation cycles, automotive radial turbines experience transient conditions, whereby the same operate at very high blade speed ratios and, thus, at very low power outputs. Under those conditions, the turbine power output might not be enough to feed the mechanical power needs of the compressor. Typical fast one-dimensional full engine simulations rely on steady-state performance maps to characterize the turbocharger. Due to the restricting compressor braking power, extreme off-design measurements cannot be obtained in standard gas stands without using an external brake instead of the compressor or without using a motor attached to the turbocharger shaft. Such turbocharger assemblies cause shaft balancing issues inherent to the connection to a brake operating at high rotational speeds or need basic changes of the turbocharger geometry. This paper presents a novel approach for turbine performance map measurements at very low expansion ratio and very low mass flow without the aforementioned issues. The method uses the turbocharger compressor as a centrifugal turbine, providing mechanical power to the shaft and enabling turbine performance measurements from points of very high expansion ratio up to very low pressure ratio. It is even possible to measure at almost zero flow rate in the turbine when it consumes shaft power instead of producing it. This experimental procedure that can be applied to whatever turbocharger produces valuable information for the development and validation of turbine performance models aiming to extrapolate its behaviour at off-design conditions.
\end{abstract}

Keywords: Turbocharger, Model, Mean-line model, Radial turbine simulation, Off-design, High BSR

\section{Introduction}

In traffic conditions, where engines change their speed frequently their mean air consumption changes additionally to the pulsating flow that can be found at the turbocharger turbine inlet. Hence, the turbine has to operate at extreme off-design conditions up to very high BSRs, very low mass flow, and zero power outputs. Such conditions can occur in urban driving cycles, which are part of the EURO5 and later the EURO6 [1] (and also, at engines with low number of cylinders or with cylinder deactivation techniques). Since the turbine map measurement is usually realized by means of stationary experiments, this paper presents a novel procedure to characterize the turbine at high BSRs and stationary flow. Such types of systematic measurements close to the zero isentropic turbine efficiency point without modifying turbocharger parts cannot be found in the literature yet.

Engine manufacturers rely on fast one-dimensional models during the engine development. Thus, good methods for extrapolating the turbocharger performance during off-design conditions are needed. A lot of effort has been put into this area lately. Approaches such as the one by Payri et al. [2], which uses a

\footnotetext{
*Corresponding author. Tel: +34963877650; fax: +34963877659

Email address: luiga12@mot.upv.es (Luis Miguel García-Cuevas)

$U R L$ : www.cmt.upv.es (Luis Miguel García-Cuevas)
} 
physically based yet fast method for computing the turbine performance maps, or the models by Romagnoli and Martinez-Botas [3] and Zhu et al. [4] for stationary flow modeling were published. Further models for transient computations like in Rajoo et al. [5], Chiong et al. [6], and Galindo et al. [7] are available. All these models have to cope not only with off-design conditions, but also with highly pulsating flow during transients, so a lot of effort has been put into producing fast and accurate one-dimensional models for engine simulations $[8,9,10]$. Also these transient models rely on the experimental data of static maps as well. All this modeling effort has to be validated using experimental data of extreme off-design conditions. Thus, a method to provide such results is highly valuable. A good prediction of the turbocharger behaviour in these operating conditions can be used to optimise the engine control or even physical parts such as the exhaust manifold [11].

Since heat fluxes influence the efficiency of small sized geometries in particular, like shown by Serrano et al. [12], these have to be computed during the simulation to supply reliable data. A method to obtain the complex system of internal heat fluxes, which occurs in turbocharger geometries, during experiments has been proposed by Serrano et al. [13]. The correlations for external heat transfer can be obtained using procedure presented by Payri et al. [14]. By means of the gained measurements heat flux models like presented by Serrano et al. [15] can be used to transform regular turbine maps into the needed adiabatic maps. When measuring high BSR points the turbine operates at extremely low power outputs, whereby even low heat fluxes, which are negligible at normal operating point measurements, are from even higher importance, as it has been shown by Serrano et al. [16].

Due to the energy equilibrium of turbine power, compressor power, bearing losses and heat losses, the compressor power consumption has to be low for measurements at very low turbine power outputs, which can cause compressor surge. At the same time the turbine experiences a limitation due to the highest possible braking compressor power, which is affected by choking. Thus, measured turbocharger maps are naturally restricted to a narrow range of BSRs.

There are several works in the literature that propose methods for a proper characterisation of several parts of the engine during transient and off-design conditions [17], but there are only limited references for measuring only the turbocharger. In past publications by Romagnoli and Martinez-Botas [3], Bellis et al. [18] and Smiljanovski et al. [19] the potential of an electrical brake instead of a compressor wheel as a power consuming part is pointed out. With the use of a brake, the consumed power can be reduced down to zero. At this specific running point the turbine still produces power to overcome the bearing and heat losses. Thereby, this method for achieving low turbine efficiencies is restricted to the zero mechanical efficiency point, where the turbine especially at high rpms produces power outputs much bigger than zero. Reversible brakes could be used for pushing the limit to even lower measurable turbine power, even though this procedure is just eligible for lower rpms due to arising balancing issues [20], when increasing the rotational speed. An electrically assisted turbocharger has successfully been tested with extreme low and even negative mass flows by Terdich [21] also for higher speeds. For the testing of common turbochargers a modification towards a electrically assisted assembly is not feasible, as the thermal characterization changes and the effort is remarkable. Salameh et al. [22] replaced the compressor wheel with a designed turbine wheel to supply extra energy to the shaft.

Instead of using low mass flows on the compressor side, the compressor could be fed by pressurized high mass flow rates making the compressor working at pressure ratios lower than one. When the mass flow can be increased enough, the compressor is able to act as a centrifugal turbine and to produce the necessary power to overcome the bearing losses. Hence, measurements at zero turbine power output and thus, at zero efficiency are achievable.

Measurements of radial compressors at pressure ratios lower than one can rarely be found in the literature. Pucher [23] fed the turbocharger by means of an additional compressor upstream of the turbo compressor to expand the achievable mass flow range of the turbo compressor. Leufvén and Eriksson [24] were able to measure non-modified radial compressors at pressure ratios lower than one with a similar test bench by supplying a compressor inlet pressure of up to two bar for low rotational speeds. Since the compressor consumes higher mass flows when reaching pressure ratios lower than one with increasing speed, the power of the pressurizing facility is the limiting factor. Also, at very high speeds the choking mass flow will be reached before arriving to the map region of gas expansion. Wallace et al. [25] and Najjar and Akeel [26] showed 
that the compressor map can be expanded significantly by introducing a swirl component in the compressor inlet, what can result in later choking of the compressor wheel in the zone of compression ratios higher than one. Furthermore, Müller et al. [27] have used a circumferential loading by introducing a swirled inlet flow at the blade tip to allow the compressor to run as a centrifugal turbine. However, it requires significant changes of the casing geometry.

In this paper an experimental procedure to supply measurement data at extreme turbine off-design conditions is presented. The proposed procedure works without any change of the turbocharger geometry, so that it can be easily used for different turbochargers. To minimize heat transfer, tests have been executed under quasi-adiabatic conditions. Gained results supply needed data for validating extrapolation models or CFD simulations in a broad range. This paper includes the following sections: first, the theoretical background of the turbine testing is given; second, the experimental method is shown; third, experimental methodologies, obtained results, and limitations are presented and discussed; last, main conclusions are written.

\section{Theoretical background}

\subsection{Turbine testing principle}

The main problem when trying to measure turbocharger turbine performance in a wide range of operating conditions is the lack of a suitable braking capacity of the remaining turbocharger parts. For high powers, the mechanical losses due to friction can be risen by using a high viscosity oil or the compressor can be forced to consume more power by rising the density of the air even at its inlet and operating with high reduced flow rates. For low powers, a low viscosity oil can be used and the compressor can be operated near its surge line with low density at its inlet. Even when doing this, the measurable range in the turbine map for a given reduced speed is small Galindo et al. [28]. For reaching higher and lower power outputs, a brake can be used. This leads to system disassembling and reassembling with associated shaft balancing issues that arise at high rotational speeds of automotive turbochargers. Anyway, no brakes have been found in the literature (nor electric neither hydraulic ones) for measuring turbine performance well over $100 \mathrm{krpm}$. Furthermore, no commercial equipment for measurements at such or higher rotational speeds without severe modifications of the turbocharger shaft and bearing system are readily available.

Another possibility is to force-feed the turbocharger compressor, without modifications of the shaft or of the rotor and thus, avoiding the shaft balancing issues. Moreover, it can be feasible to measure the full range of turbine operating conditions, which can be found in normal automotive driving cycles.

According to Figure 1, high turbine power outputs (B-A) are measurable by running the compressor in the range of A' to A within the normal range of compressor power consumption and, thus providing braking power. By force-feeding the compressor, points beyond A' are achievable. In addition the compressor can be even made to work as a centrifugal turbine, producing enough power to drive the turbocharger shaft. To realize this has been the main challenge to obtain measurements for the turbine side in a broad range.

For doing so, the compressor pressure ratio has basically to become lower than one (Point C) to operate in the range of C' $\left(\eta_{\text {turb., mech. }}=0\right)$ and D, where the compressor produces a net power output $\left(W_{\text {comp. }}>0\right)$. When running at high speeds the compressor may starts to choke at pressure ratios bigger than one. Then, the needed reduced mass flow to gain power output is not obtainable and the zero efficiency point D of the turbine is hard to reach at these speeds.

\subsection{Potential in common configurations}

Euler's turbomachinery equation has been used for computing the power output of a compressor rotor:

$$
\begin{aligned}
\dot{W}_{\text {comp. }}= & \dot{m}_{\text {comp. }} \cdot \omega \cdot\left(\bar{R}_{1} \cdot c_{\theta, 1}\right. \\
& \left.-R_{2} \cdot c_{\theta, 2}\right) .
\end{aligned}
$$

Where $\dot{W}_{\text {comp }}$ is the compressor power output, $\dot{m}_{\text {comp }}$ is the compressor mass flow rate, $\omega$ is the rotor rotational speed, $\bar{R}_{1}$ is the mean radius at the rotor inlet, $R_{2}$ is the radius at the rotor outlet and $c_{\theta, 1}$ and 

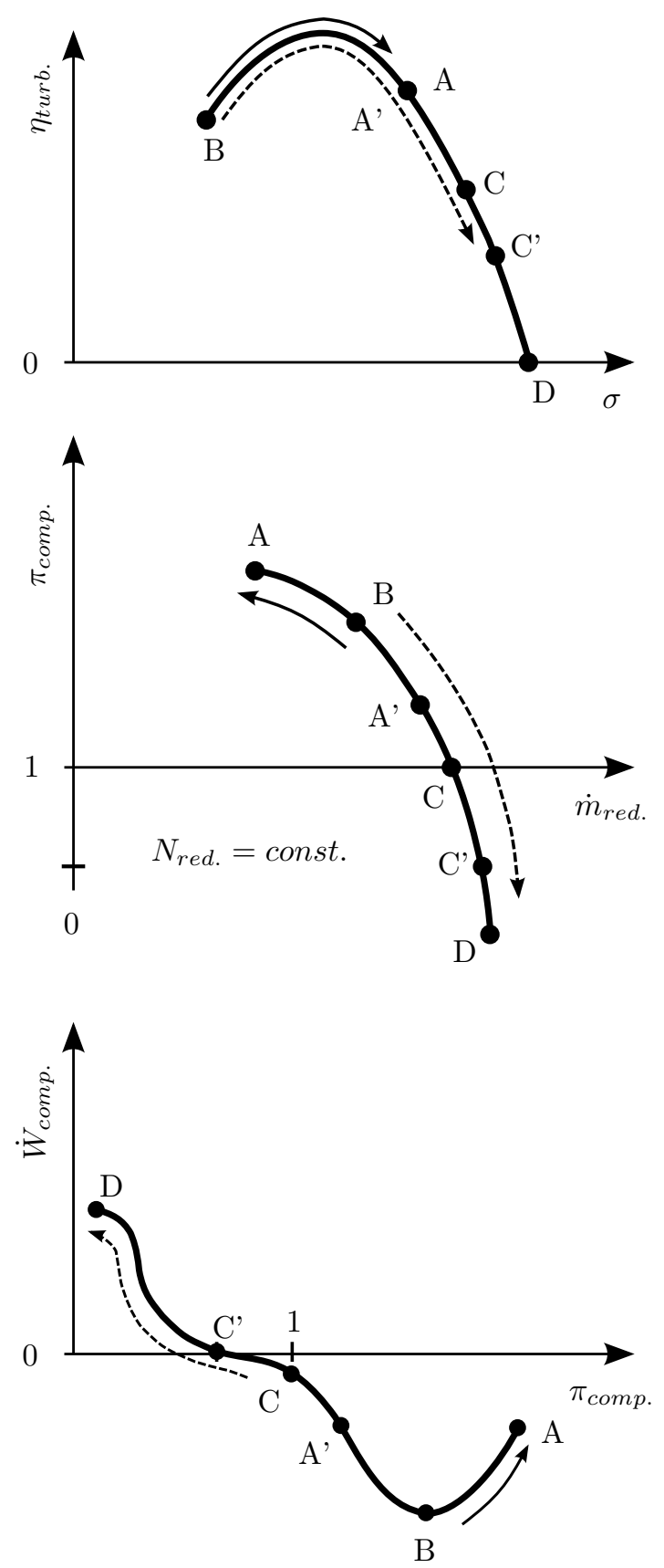

Figure 1: Relation between compressor and turbine running condition

$c_{\theta, 2}$ are the tangential speeds in an inertial reference frame fixed in the center of the rotor at its inlet and at its outlet (Figure 2).

In common cases with axial flow inlet $c_{\theta, 1}$ is negligible and $c_{\theta, 2}$ is bigger than 0 , leading to a power consumption (negative power output) as figure Figure 2 (a) shows. If the compressor flow rate is high 
enough and the rotational speed is low the tangential speed at the rotor outlet in the relative reference frame can be high enough to produce a negative tangential speed component in the inertial reference frame $c_{\theta, 2}$ as Figure 2 (b) illustrates. According to Equation 1 this results in positive power outputs. This can be
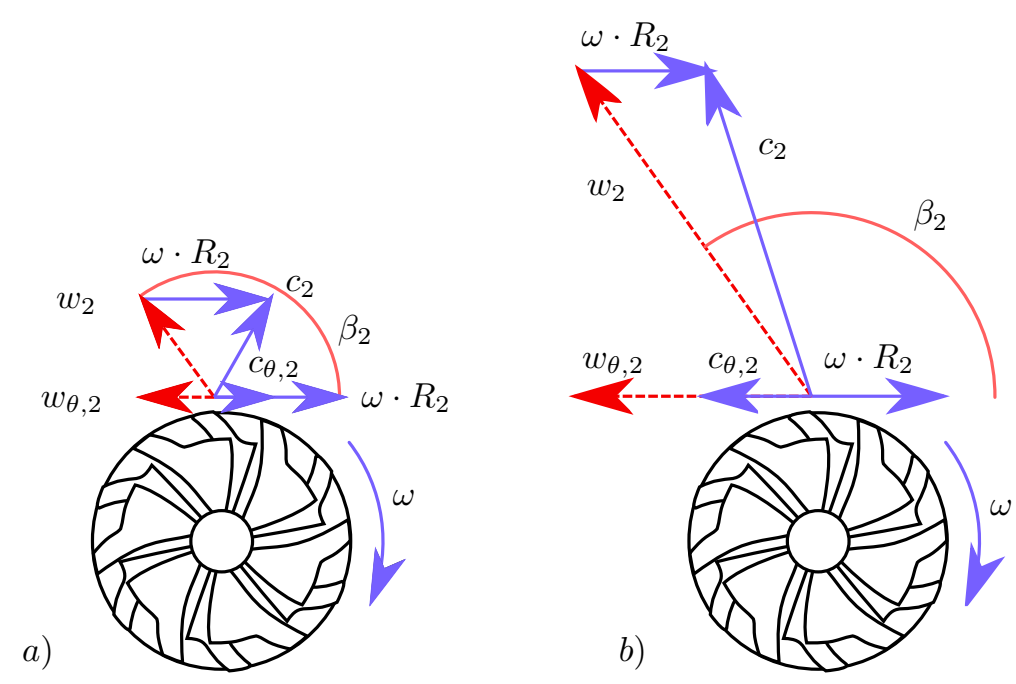

Figure 2: (a):Velocity triangle at normal operating condition; (b):velocity triangle with high flow rate

achieved by force-feeding the compressor with pressurized air and high mass flows at its inlet, making it to operate at lower than one pressure ratios. In these conditions, the turbine might be measured with very low power outputs and at a given turbocharger speed, as the compressor provides part of the power consumed in mechanical losses. In some cases, the compressor might provide even more power than the mechanical losses, and the turbine can be measured at the zone of very low pressure ratios, where it consumes mechanical power instead of producing it.

A simple model can be used to estimate the trends of limitations faced during the experimental campaign and was also used to show the potential of several setups, which were installed step by step into the test bench. Objective of the model is to deliver the unknown parameter $c_{\theta, 2}$ of Euler's turbomachinery Equation 1, calculating the relative outlet velocity by means of the rothalpy conservation equation, rearranged as:

$$
w_{2}=\frac{\sqrt{2 \cdot c_{p} \cdot T_{t, 1} \cdot\left[1-\left(\frac{p_{t, 1}-\Delta p_{t}}{p_{2}}\right)^{\frac{1-\gamma}{\gamma}}\right]}-}{-\omega^{2} \cdot\left(\bar{R}_{1}^{2}-R_{2}^{2}\right)}
$$

Here $\Delta p_{t}$ is the sum of the NASA loss models for incidence and passage losses by Futral et al. [29]. When the critical pressure ratio is reached, the NASA shock model is used. Assuming that the flow exits the passage with the blade angle $\beta_{2}$ defined like in Figure 2 and thus, not considering deviation or estimating a slip factor, the velocity component $c_{\theta, 2}$ can be calculated as:

$$
c_{\theta, 2}=w_{2} \cdot \cos \beta_{2}+\omega \cdot R_{2} .
$$

Results of the calculation of the compressor power with low inlet temperature of $50{ }^{\circ} \mathrm{C}$ are presented in figure Figure 3. The expected maximum measurable rot. speed where the compressor operates as a centrifugal turbine is rather low and the needed pressure ratio rather low. When the blade tip tangential speed rises, the flow speed at the rotor outlet has to rise to produce a negative tangential absolute speed component, as Equation 3 shows. Since the available compressor inlet pressure is usually restricted by the maximum 


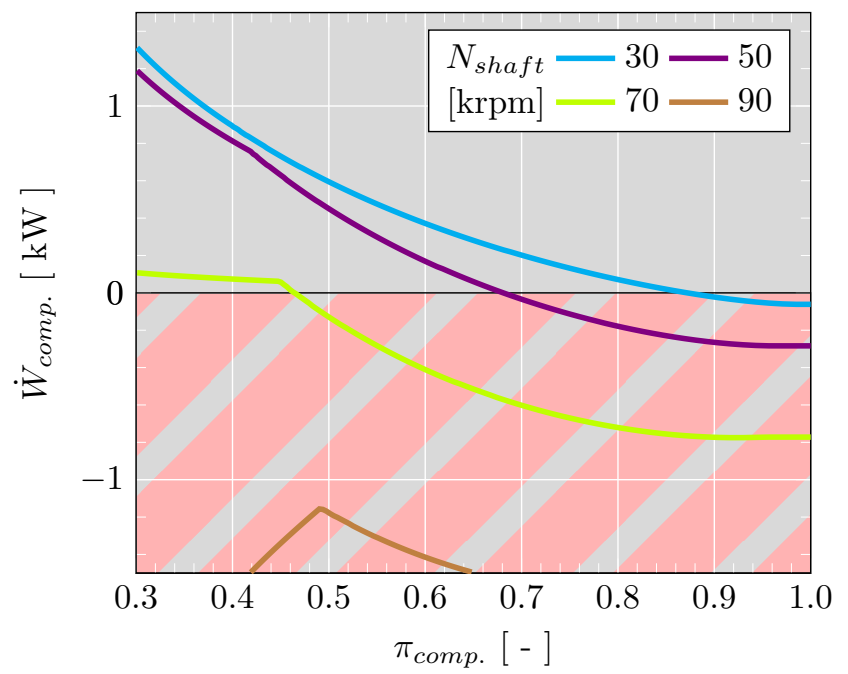

Figure 3: Compressor model results of compressor power output with $50^{\circ} \mathrm{C}$ inlet air temperature

power of the air supplying units, just very low speeds are measurable with such an unmodified test configuration. Additionally compressor choking could take place before a sufficient net compressor power output is noticeable and no further velocities may be reached.

Experimental results of a complete compressor map measurement, where the compressor was not configured but force-fed to reach very low pressure ratios are presented in section 4. Procedures for realising the needed compressor power production and thereby obtainable results on the turbine side at very low turbine efficiencies are presented in section 5 .

\section{Experimental method}

This section contains the description of the experimental test facility used in the present work. The gas stand setup and its control will be introduced; then the turbocharger installation is described.

\subsection{Gas stand setup}

The scheme of the final gas stand arrangement can be found in Figure 4. A truck engine is used as a gas generator for the turbine. Its crankshaft is connected to a reversible asynchronous motor, that can brake and power the engine, so the temperature at the inlet of the turbine can be controlled by the amount of fuel injected regardless of the rotational speed of the engine. The engine discharges towards a plenum (a) that is connected to the turbine and to the exhaust line, being the latter connection controlled by means of two automatic valves (1). When the flow rate through the turbine has to be set lower than the engine flow rate, this plenum valves can be opened to divert a part of the flow and reduce the turbine pressure ratio.

The reversible asynchronous motor has two heads: one end is connected to the engine crankshaft, and the other one is connected to a gearbox that drives an auxiliary screw compressor. This compressor is used for boosting the engine and as a gas generator for the turbocharger compressor. By controlling the rotational speed of the engine (and, thus, the speed of the screw compressor) the pressure and temperature at the engine intake and the turbocharger compressor inlet can be regulated. In combination with discharge valves in the engine intake line 2 and the turbocharger compressor inlet line 3 the loading can be adjusted for both lines independently. To manipulate the back pressure of the turbocharger compressor two electrical valves (4) are installed in parallel.

For obtaining the needed turbine measurements the turbine has initially been operating at moderate mass flow like in point A of Figure 1. At this conditions the valves (1) are in mid-position, the valves (2) 


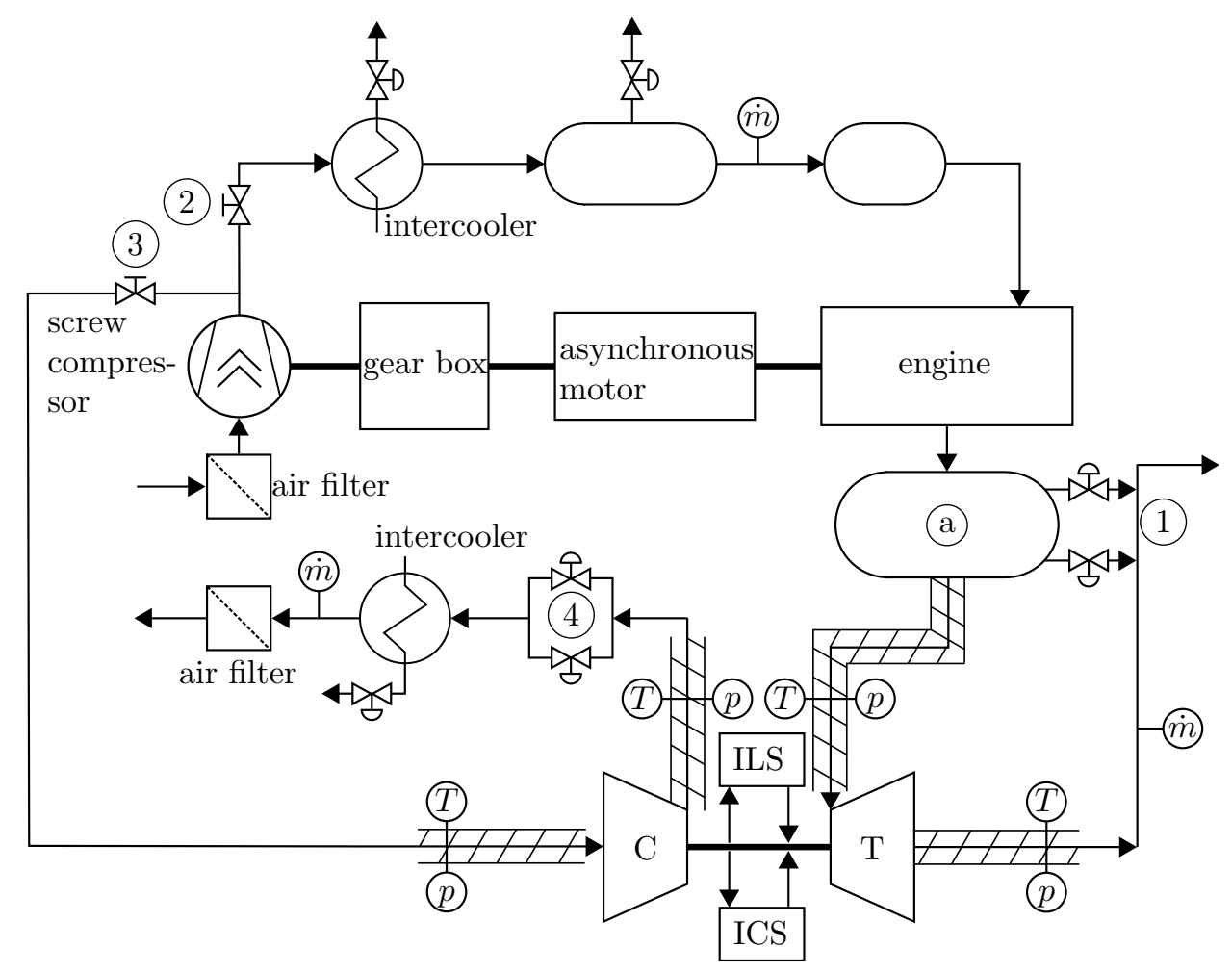

Figure 4: Gas stand scheme

and (3) are completely opened whereas the compressor outlet valves (4) are predominantly closed. First, the turbine mass flow has been increased by means of closing the turbine valves (1). In order to maintain the rotational speed the compressor back pressure has been reduced by opening the compressor valves (4) until the braking power has been sufficiently increased. This procedure can be continued until the maximum braking power is obtained, corresponding to point B in Figure 1. Following, the turbine valves (1) have been opened slowly again to measure at low turbine mass flows beyond running point A' in Figure 1. At low turbine mass flow the turbo compressor running condition is driven towards even lower compression ratios via a stepwise closing of valve (2) and simultaneous opening of valve (3). When the turbine runs with very low mass flow, at running points where the compressor has to supply supporting power (beyond C' in Figure 1), the rotational speed of the screw compressor can be risen and valves (4) can be further opened. Thus, it has been possible to force-feed the compressor additionally.

The mass flow rate is measured at the outlet of the compressor and at the outlet of the turbine, as well as at the engine inlet. The engine also counts with a fuel flow rate sensor and a blow-by flow sensor, so the composition of the gases passing through the turbine can be computed. Also, the turbine flow rate can be measured redundantly when the engine exhaust plenum valves (1) are totally closed. The mass flow rate at the compressor outlet and engine inlet is measured with hot-wire flow meters, while the turbine outlet sensor is a differential pressure, V-cone shaped flow meter [30].

The pressure and temperature probes are six diameters away of the inlet and outlet of compressor and turbine. In each of this measurement planes there are two piezoresistive transducers for pressure measurements. On the compressor side the temperatures have been measured by two K-type thermocouples, on the turbine side by four.

An independent lubrication system is used. This way, the pressure and temperature of the lubrication oil of the turbocharger can be set for each experiment. The oil flow rate is measured with a coriolis flow 
meter, its pressure with piezoresistive transducers and its temperature at the turbocharger inlet and outlet with thermocouples. The accuracy of the measurement media used in the experiment are listed in Table 1.

\begin{tabular}{lll}
\hline \hline Variable & Sensor type & Accuracy \\
\hline Gas pressure & Piezoresistive & $\pm 1250 \mathrm{~Pa}$ \\
Gas and metal & K-type & $\pm 2.2 \mathrm{~K}$ \\
temperature & thermocouple & \\
Gas mass flow & V-cone & $\pm 0.5 \%$ \\
Oil pressure & Piezoresistive & $\pm 2500 \mathrm{~Pa}$ \\
Oil temperature & RTD & $\pm 0.15 \mathrm{~K}$ \\
Oil mass flow & Coriolis & $\pm 0.1 \%$ \\
\hline \hline
\end{tabular}

Table 1: Accuracies of measurement sensors

\subsection{Turbocharger setup}

An automotive turbocharger has been measured during the experimental campaign. It has a variable geometry turbine, is equipped with a water cooling system and normally operates in $2 \mathrm{~L}$ diesel engines.

During the experimental campaign, the internal and external heat flows were kept as low as possible, so that the water cooling system was disconnected. The turbocharger as well as its inlet and outlet ducts were also thermally insulated. The flow temperature at the turbine inlet was kept close to the lubrication temperature, minimizing the internal heat transfer. Even after taking these measures, the flow evolution differs from the fully adiabatic one. Low turbine power is affected by residual heat fluxes, which would normally be considered as negligible as the turbine power output is of higher magnitude. Effectively, the power output can be obtained by measuring the enthalpy leap in the turbine, Equation 4:

$$
\dot{m}_{t u r b} \cdot \bar{c}_{p} \cdot\left(T_{3 t}-T_{4 t}\right)=\dot{W}_{t u r b .}+\dot{Q}_{t u r b}
$$

Where $\dot{m}_{\text {turb. }}$ is the turbine flow rate, $\bar{c}_{p}$ is the average isobaric specific heat capacity of the evolution inside the turbine, $T_{3 t}$ is the turbine inlet total temperature, $T_{4 t}$ is the turbine outlet total temperature, $\dot{W}_{t u r b}$. is the turbine power output and $\dot{Q}_{t u r b}$. is the heat transfer to the oil and to the turbine casing. When the absolute value of the last term is much smaller than the former, which is a normal condition during the almost adiabatic measurements (with $\dot{Q}_{t u r b}<0$ ), the turbine power output is easily approximated with a high degree of precision from the enthalpy leap. However, at very high BSRs, the power output is low enough to be comparable to the residual heat flow, so that it has to be additionally measured.

This residual heat flow has been measured using the method described in Serrano et al. [12] and [13]. 15 thermocouples have been placed in five different planes of the turbocharger, and the internal heat flow has been computed using a one-dimensional heat flow model. The internal conductances were obtained in a different testing campaign. The external heat flow has been computed by measuring the temperature of the thermal insulation skin at the turbocharger and inlet and outlet ducts, as well as the ambient temperature and air speed. During the turbine measurements these turbocharger casing temperatures have been monitored. After changing the turbine and compressor running conditions, the measurements has been taken as soon as the temperatures are stabilized. This is from growing importance, when measuring at low turbine power.

Four rack positions have been set for the variable geometry turbine stator during the experiments: $10 \%$, $30 \%, 60 \%$ and $80 \%$ of displacement. Whereby $0 \%$ marks the closest stator position and $100 \%$ the widest stator opening. At each, 6 different reduced rotational speeds have been measured: 1710, 2830, 3890, 4890, 5830 and $6715 \mathrm{rpm} / \mathrm{K}^{0.5}$. Extremely high blade speed ratios have been measured for the first four reduced speeds, which are equivalent to a physical speed range from $45 \mathrm{krpm}$ to $130 \mathrm{krpm}$ when operating at a common turbine inlet temperature of around $700 \mathrm{~K}$, and from $56 \mathrm{krpm}$ to $160 \mathrm{krpm}$ at around $1100 \mathrm{~K}$. This is a common range for the diesel engine exhaust gas temperature upstream of the turbine. 


\subsection{Procedure Check List}

1. Prepare test bench; Set oil temperature; Adjust VGT position.

2. Set valves in starting position.

3. Start the installation preferably with high mass flow to achieve fast thermal stabilization. (30 min to $60 \mathrm{~min})$

4. Change valve positioning according to the aforementioned description to modify the operating point.

5. Wait for thermal stabilization. (5 min to $10 \mathrm{~min}$ )

6. Take measurements.

7. Continue with 4. until the desired points are measured or until one of the below mentioned limitations are reached.

\section{Compressor measurements without modification}

Since the regime of the compressor plays a significant role for the obtainable turbine measurements the compressor map results are shown in Figure 5(a) first. Aside of the traditional compressor map also the specific enthalpy change is plotted in Figure 5(b). Thus, the potential of running the turbine with

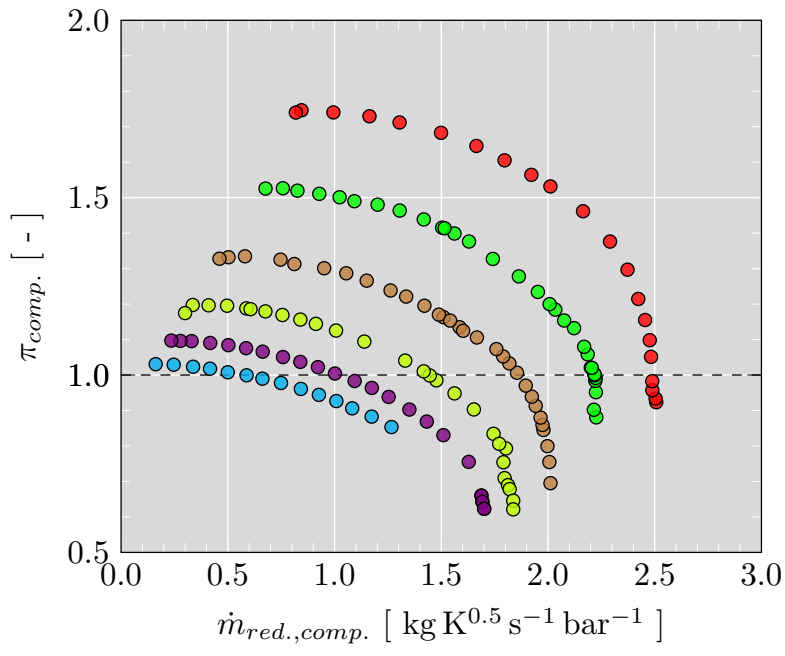

(a) Compressor map without modification

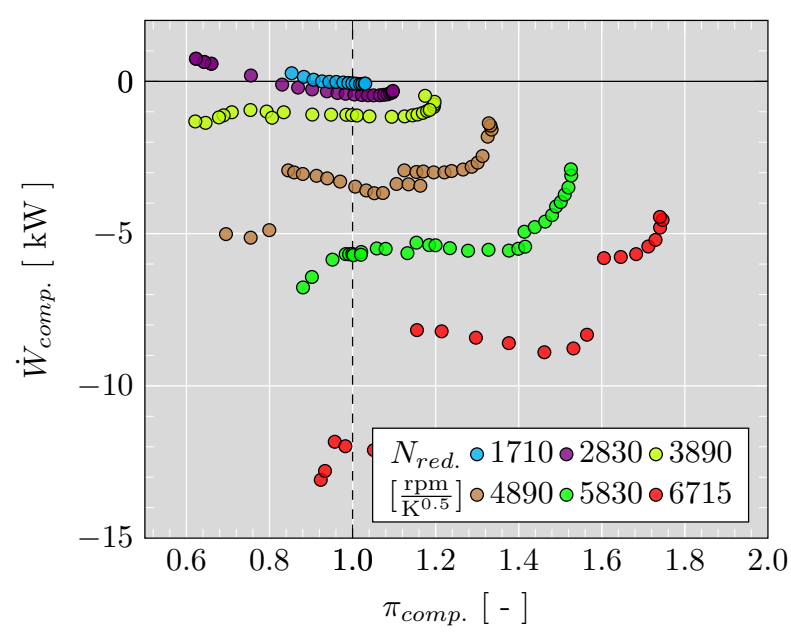

(b) $\dot{W}_{\text {comp. }}$ without modification

Figure 5: Compressor maps in unmodified configuration

the positive power output of the compressor can be seen as relatively small. For the two lowest reduced speeds positive power outputs are achievable: for $1710 \mathrm{krpm}$ from moderately low compression ratios less than 0.91 ; for $2830 \mathrm{krpm}$ the compression ratio has to pass even below 0.83 . However, these positive power outputs are rather low. At $3890 \mathrm{krpm}$ and higher speeds no net positive compressor power output has been achieved. Hence, some turbine measurements below the mechanical turbine efficiency are feasible by means of simply force-feeding the compressor, though the number of points is low. To expand the limiting number of measurable points some modifications have to be made, like presented in the following sections.

\section{Enhanced testing methodology and discussion of the results}

Anticipating the experience of the performed measurements it can be said, that the need of high compressor mass flows and operating at compression ratios lower than one has several inherent limitations for common test benches and common compressors, which have been overcome during the performed measurements. Thereby, three different setups have been used on the compressor side to obtain as much turbine measurements at high BSRs as possible. These arrangements for high BSR measurements have kept identical for speedlines over changing VGT openings. 


\subsection{Inlet Guide Vane}

Examining the Equation 1 shows that the possible control of the inlet velocity has been unused yet. Thus, the aforementioned limitation can be risen by rotating the flow at the rotor inlet. Indeed, by using a properly sized IGV device, the absolute tangential speed $c_{\theta, 1}$ can be risen to non-negligible values like shown in Figure 6, thus contributing to the compressor net positive power output. Thereby, the necessary power

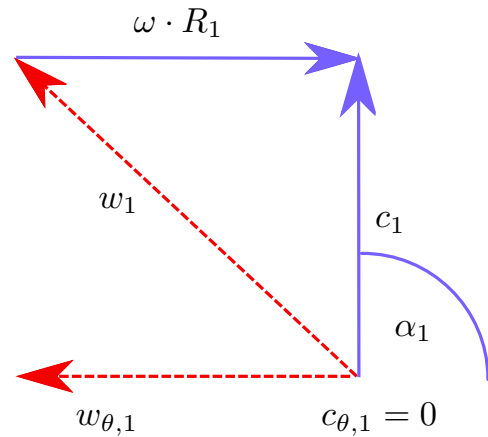

a)

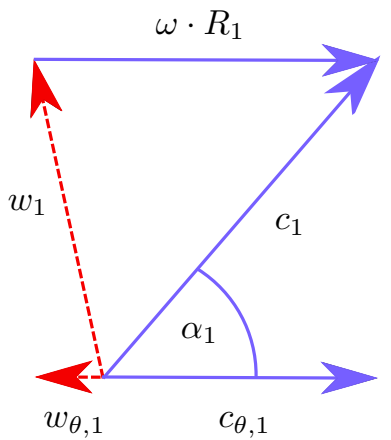

b)

Figure 6: (a): Velocity triangle at normal operating condition; (b): velocity triangle with inlet swirl

output can be obtained at lower reduced mass flows. In Figure 7 the modeled net compressor power output can be noticed at lower pressure ratios and at higher speeds than in Figure 3 without swirl component. Furthermore, the rotor choking limit itself could be pushed towards higher reduced mass flows since the

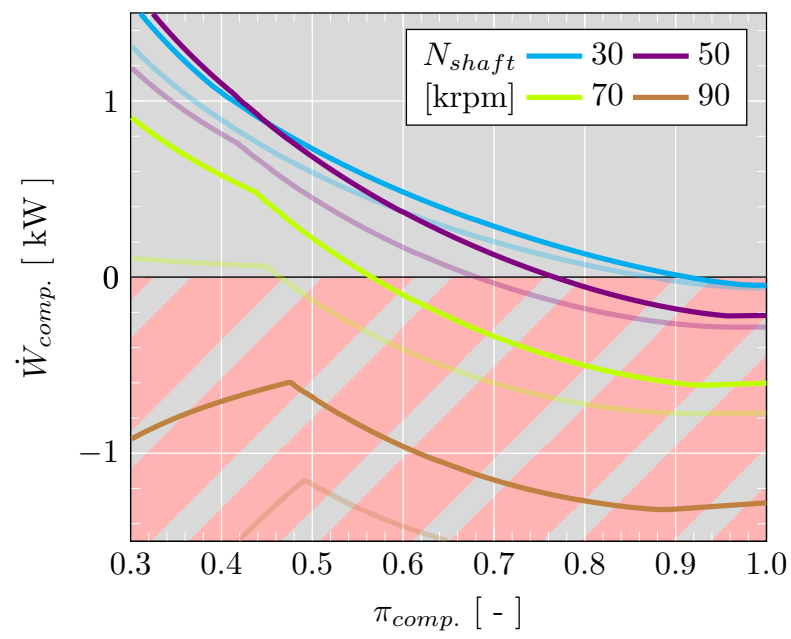

Figure 7: Compressor model results with $50^{\circ} \mathrm{C}$ inlet temperature and imposed swirl component $c_{\theta, 1}\left(\alpha_{1}=50^{\circ}\right)$; compared with results of Figure 3 (light color lines)

relative inlet Mach number decreases Najjar and Akeel [26].

The assembled IGV is shown in Figure 8. It has been positioned $55 \mathrm{~mm}$ upstream of the compressor inlet. The IGV has five arc shaped blades, which are slightly twisted in circumferential direction, with $1 \mathrm{~mm}$ thickness and a reduced blade-width at the trailing edge to decrease the boundary layer separation. These blades are extruded from a rotated NACA0012 profile (Jacobs et al. [31]), which acts as a hub. In addition the IGV blade angle is optimized by the use of CFD simulations to guarantee an average flow angle between $45^{\circ}$ and $55^{\circ}$, according to the definition in Figure 6, and a low pressure drop across the full operating range. 


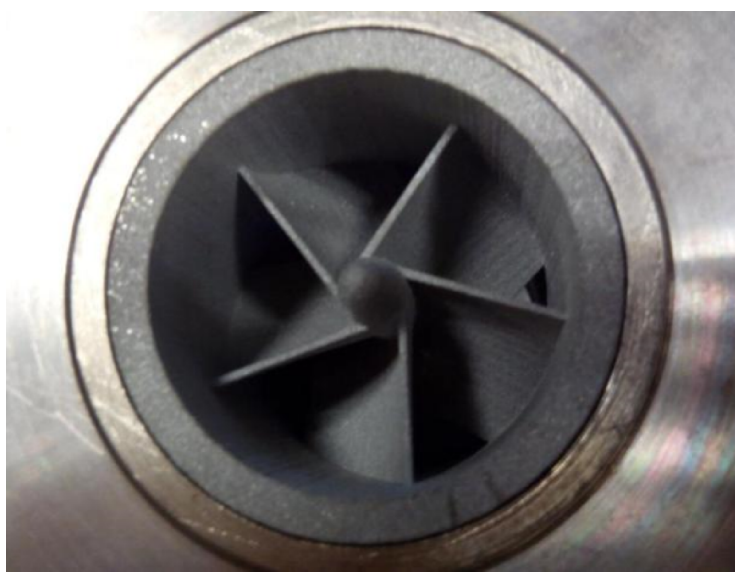

(a) Inlet view

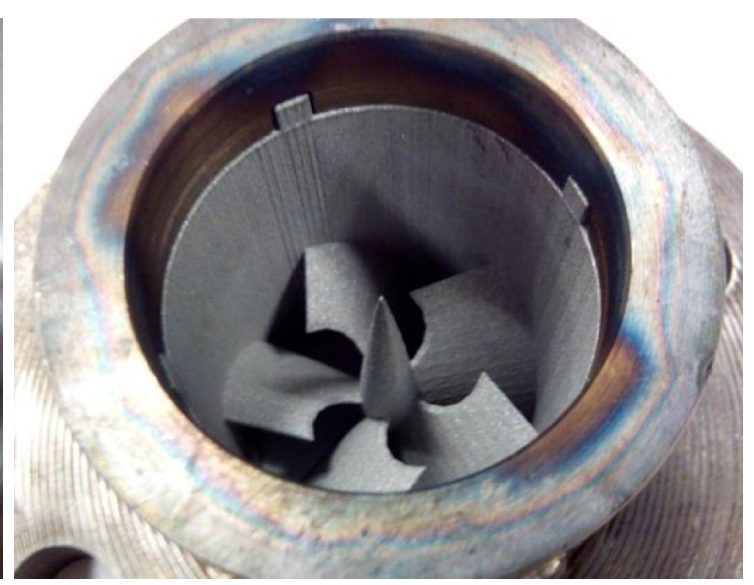

(b) Outlet view

Figure 8: IGV upstream of the compressor

\subsubsection{Compressor side}

During all measurements at very low turbine mass flow rates, the IGV has been used to guide the inlet flow of the compressor. When measuring at normal operating conditions, it is not necessary to support the turbine with power gained by the compressor and the swirl at low compressor mass flow would result in high incidence angle (Wallace et al. [25]). Thus, the IGV was detached to avoid compressor surge during the measurements at normal turbine operating conditions of lower BSRs and high turbine efficiencies.

By means of the IGV the compressor power output can be risen high enough, so that the turbine efficiency map at low turbine efficiencies has been measurable between the reduced rotational speeds $1710 \mathrm{rpm} / \mathrm{K}^{0.5}$ to $3890 \mathrm{rpm} / \mathrm{K}^{0.5}$. The characteristic compressor lines measured, while using the IGV at the inlet, are shown in Figure 9. The IGV has realized the generation of positive compressor power at a rotational speed of

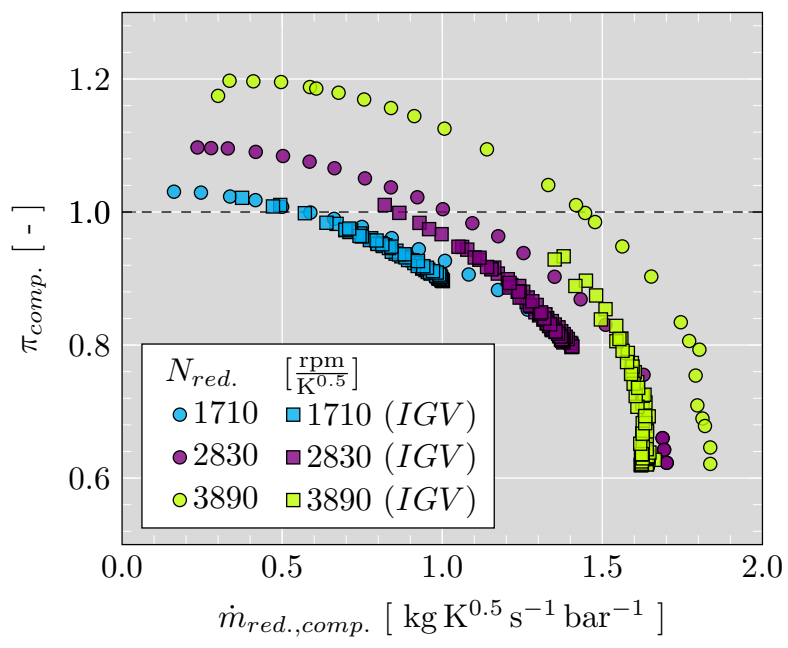

(a) Compressor map with IGV in the inlet

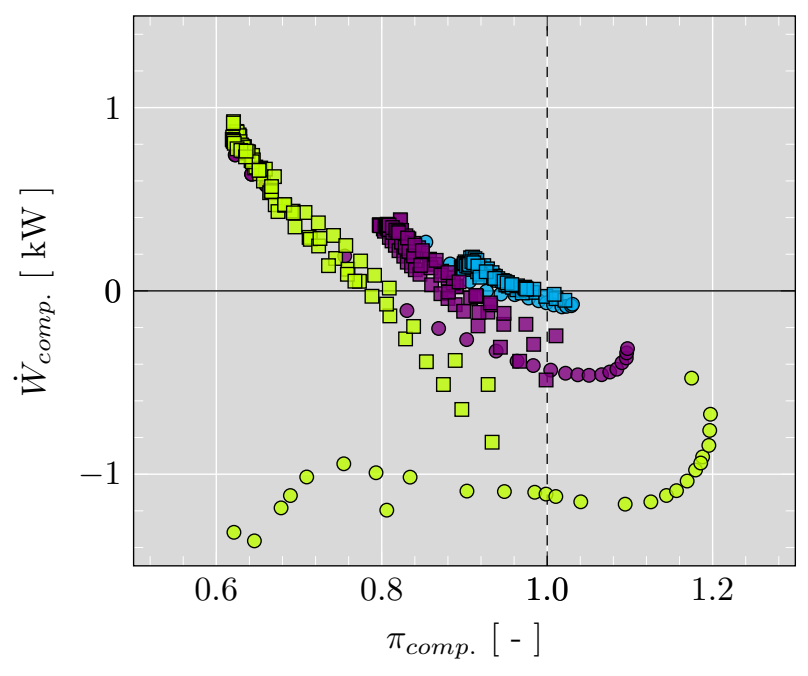

(b) $\dot{W}_{\text {comp. with IGV in the inlet }}$

Figure 9: Compressor maps with IGV in comparison with the results of the unmodified configuration

$3890 \mathrm{rpm} / \mathrm{K}^{0.5}$, which has not been possible before (Figure $9(\mathrm{~b})$ ). However, the flow starts to choke at lower reduced mass flows than without IGV (Figure 9(a)). When the compressor mass flow has been risen, choking inside of the compressor volute and diffuser has taken place, before a sufficient power can be obtained to 
achieve measurements at higher rotational speed. Thus, no further reduced speedlines at very low turbine mass flow have been measured with this method.

\subsubsection{Turbine side}

The obtained measurements are executed in high resolutions to guarantee a high reliability of the gained data. The measurement results achieved on the turbine side; together with turbine model results of the models described in the work of Serrano et al. [32] and Payri et al. [2]; are shown in Figure 10. 


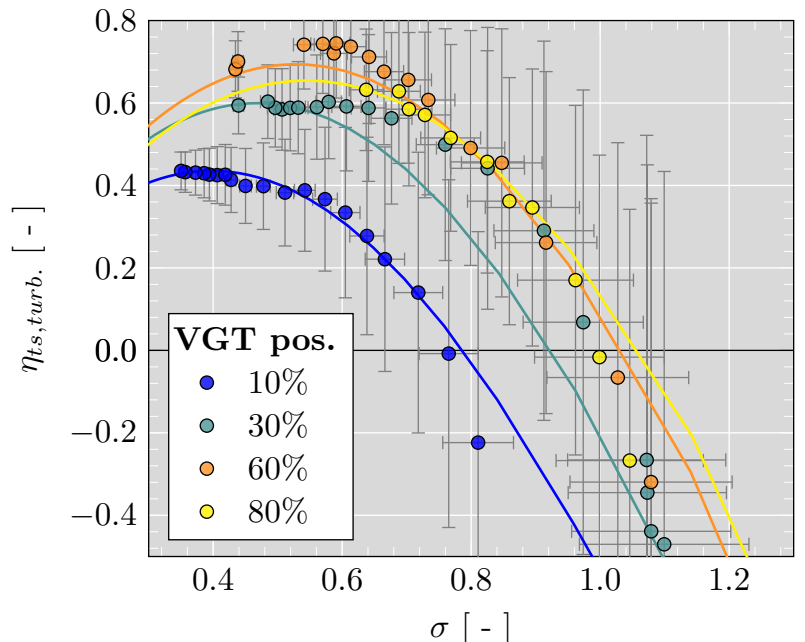

(a) Efficiency at $1710 \mathrm{rpm} / \mathrm{K}^{0.5}$

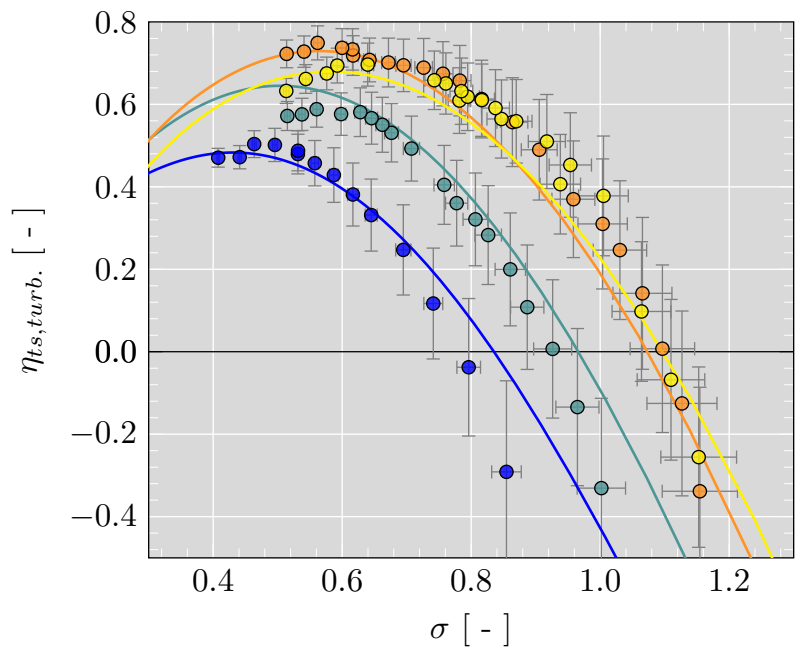

(c) Efficiency at $2830 \mathrm{rpm} / \mathrm{K}^{0.5}$

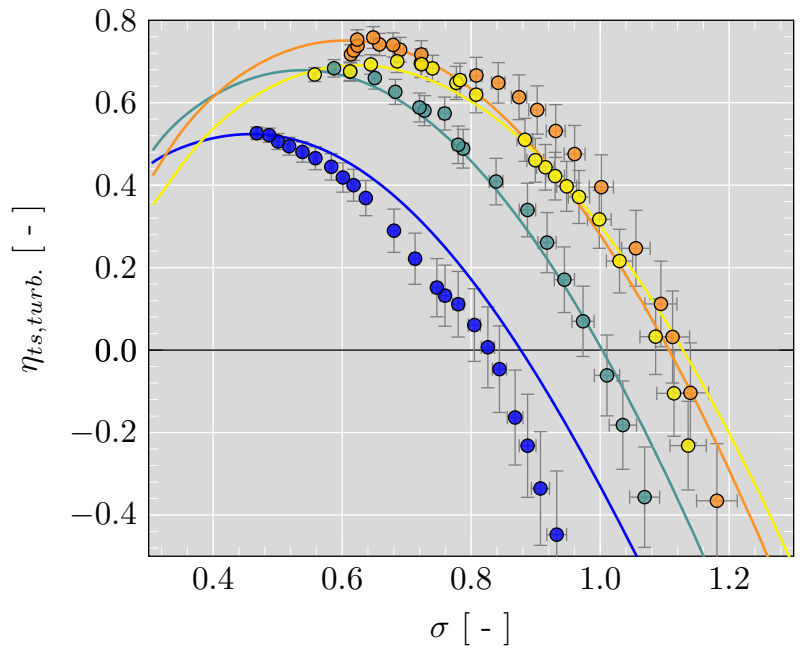

(e) Efficiency at $3890 \mathrm{rpm} / \mathrm{K}^{0.5}$

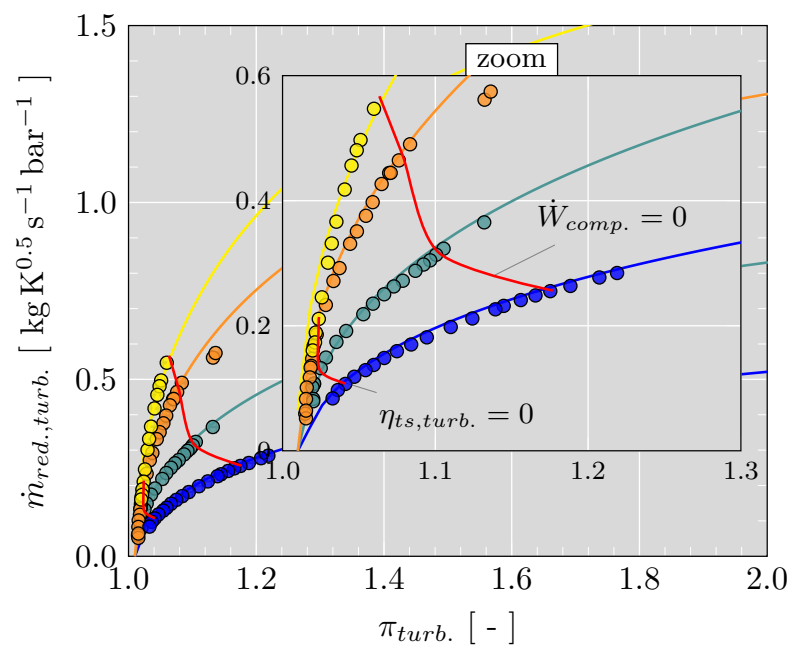

(b) $\dot{m}_{\text {red. }}$ at $1710 \mathrm{rpm} / \mathrm{K}^{0.5}$

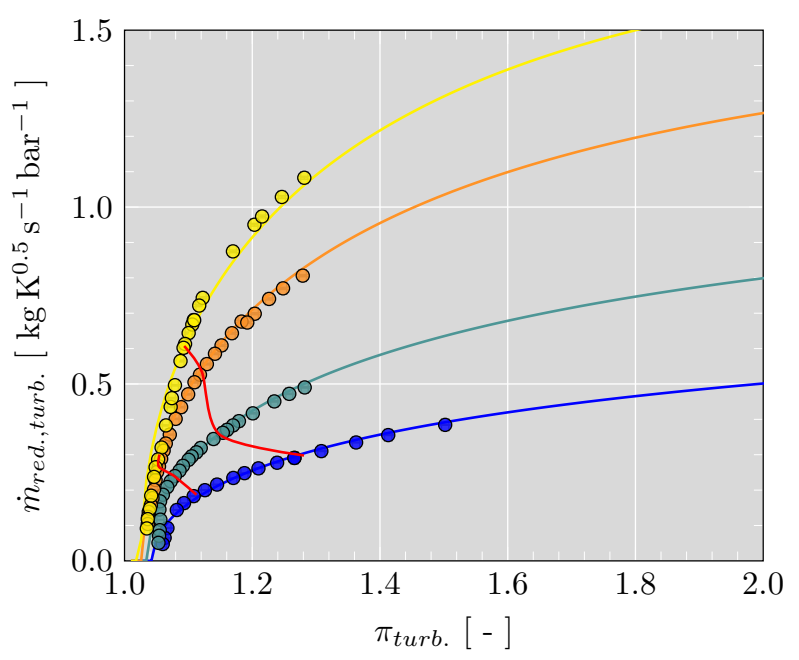

(d) $\dot{m}_{\text {red }}$. at $2830 \mathrm{rpm} / \mathrm{K}^{0.5}$

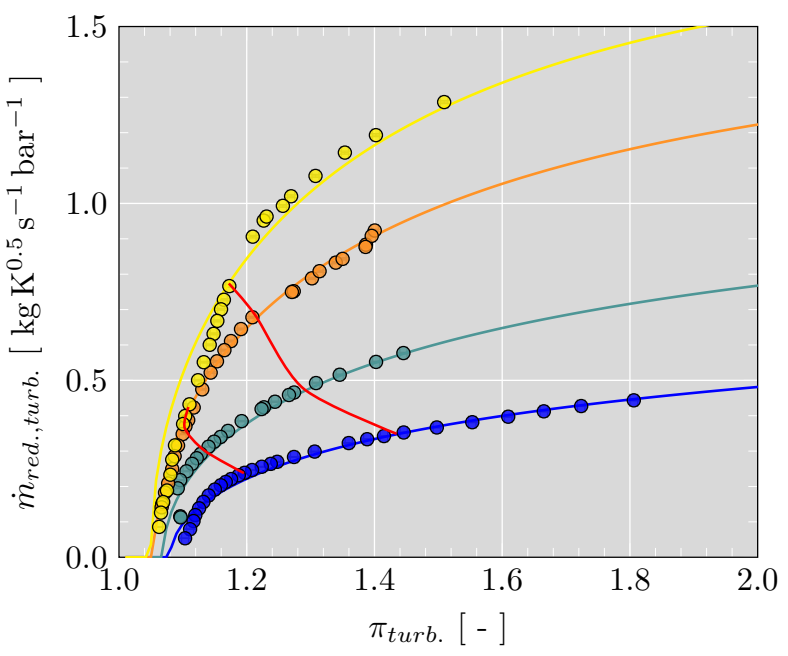

(f) $\dot{m}_{r e d}$. at $3890 \mathrm{rpm} / \mathrm{K}^{0.5}$

Figure 10: Turbine maps with IGV 
The model is fitted with five points of each speedline in normal operating range with high turbine power (lower BSR) and predicts the efficiency and mass flow for higher BSRs. Thus, the model lines can be understood as a guide for achieved results from the experiment. In Figure 10 ((a), (b) \& (c)) efficiencies are shown down to $-50 \%$ and a BSR up to 1,2 , even when further points with much lower efficiency have been measured.

In the mass flow maps, shown in Figure $10((\mathrm{~b}),(\mathrm{d})$ \& (f)), it can be seen that it has been possible to measure at very low turbine mass flow for each particular speed. Measurement discontinuities at higher mass flow in the maps of Figure 10(c) - Figure 10(f) for $80 \%$ VGT opening are caused by the detachment of the IGV. Furthermore, lines of zero compressor work and zero efficiency are added here. The line of zero compressor work visualizes the improvement of the measurement range regarding obtainable measurements with current state of the art methods Smiljanovski et al. [19]. A remarkable improvement has been gained for all speedlines by means of the presented procedure. The line of zero efficiency marks the region, where the turbine work starts to be negative. Here the turbine wheel consumes power from the shaft since the aerodynamic losses are from dominant behaviour and effect a contrary momentum/torque.

In the mass flow measurements a sudden change of the curvature in regions of negative efficiencies is conspicuous. This distinction appears strongly at 30\% VGT opening and grows with reduced speed as it is highlighted by Figure 11. It is worth highlighting, that during the mass flow measurements in this particular region unusual fluctuations have been recognized. Similar behaviour of the mass flow curves can be observed in the experimental data by Terdich [21] for $30 \%$ VGT opening at very low mass flow.

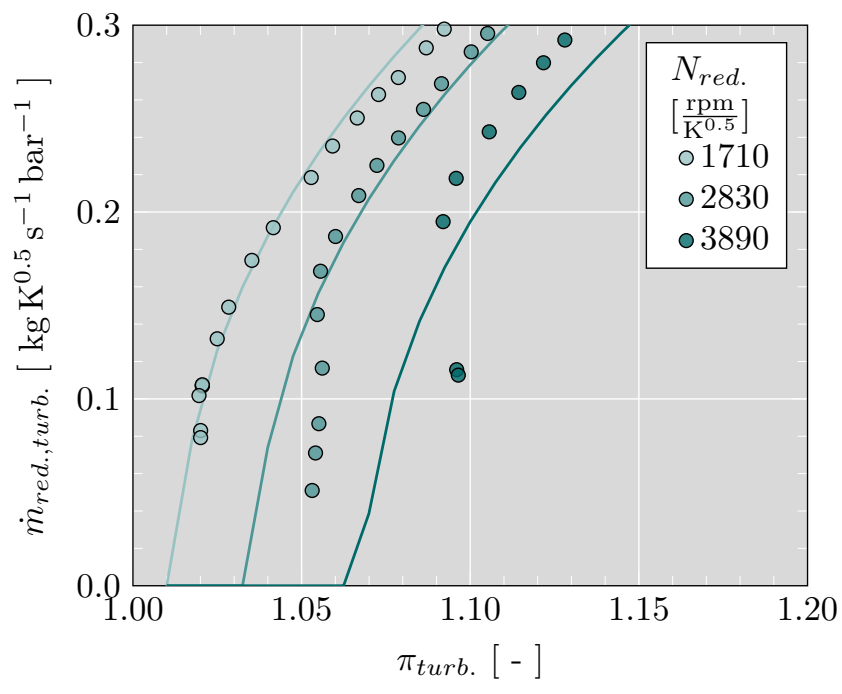

Figure 11: Conspicious behaviour of very low mass flow

Such a behaviour could be affected by small fluctuations of the VGT blades, caused by a drop of stator blade loading, loose blade positioning caused by production. Furthermore the flow could start to fluctuate before changing the direction entirely, when reducing the pressure ratio even more. A change of the flow direction has been observed by Terdich [21] at expansion ratios close to one.

Due to the low magnitude of power outputs and pressure ratios, which are measured in the extreme off-design condition, high uncertainties can occur. With common precision of k-type thermocouples of $2.2 \mathrm{~K}$ and the precision of $2500 \mathrm{~Pa}$ of the pressure probes, like shown in Table 1, along with the aforementioned conditions and at the same time not negligible heat fluxes the uncertainties in efficiency are naturally high. Hence, the inaccuracies are growing towards lower rotational speed and towards decreasing efficiency. Nevertheless a high repeatability has been stated for the efficiency and the trends match the extrapolation results. A comparison with further data is not possible since this turbocharger has not been measured by authors that propose different procedures for measuring at high BSRs like ?? and ??. The uncertainties for 
the mass flow are rather low for the full measurement range.

\subsection{Milled Volute}

After decreasing the compressor pressure ratio by means of the IGV it has been noticed, that the reduced mass flow is limited again as shown in Figure 9. This time by volute and diffuser choking, since the compressor volute requires tangential rotor outlet flow with an opposite orientation (Figure 2), which results in high mixing and pressure losses in the volute. Furthermore, the compressor area ratios are not designed for gas expansions.
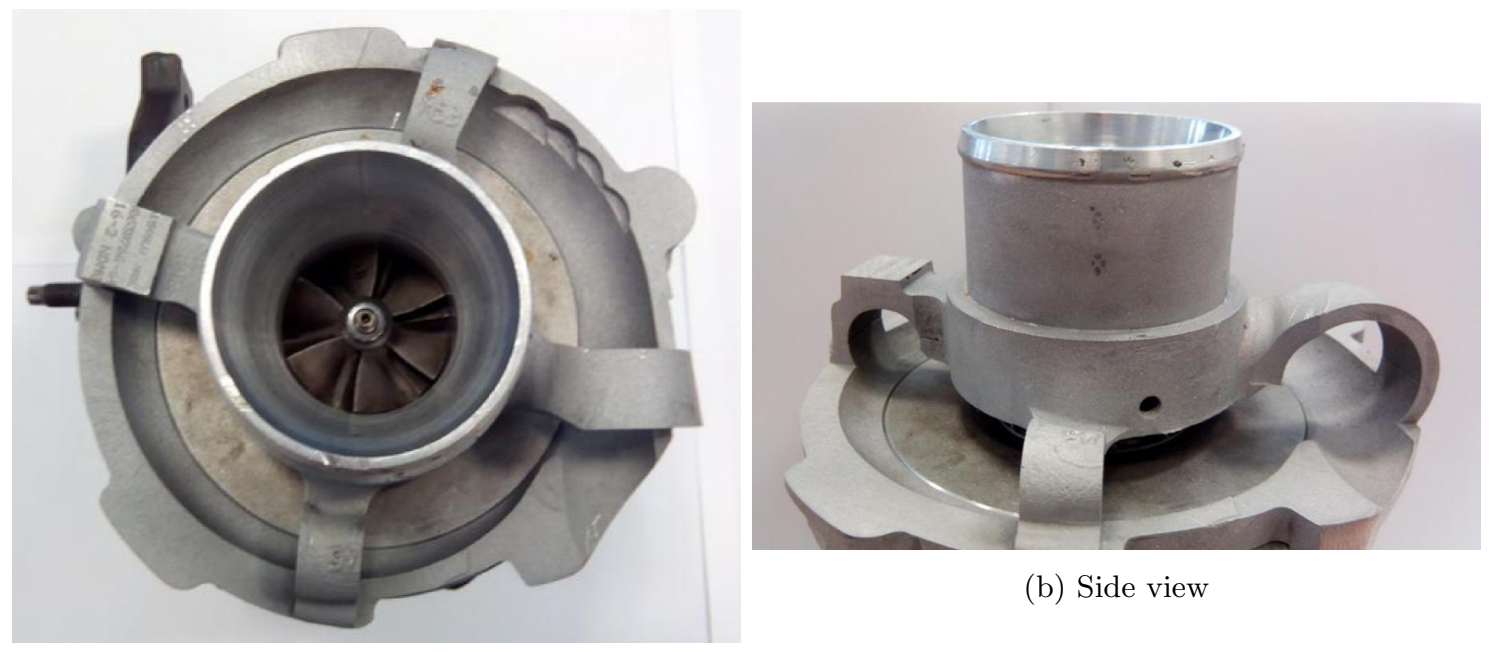

(b) Side view

(a) Top view

Figure 12: Milled compressor casing

Hence, this limitation can be overcome by milling the compressor casing, maintaining its inlet pipe but removing material from the outlet diffuser and volute, so that the rotor expands towards the ambient as it can be seen in Figure 12.

\subsubsection{Compressor side}

To reach the following required reduced speed a compression ratio close to 0.5 is required while expanding to the ambient pressure. Thus, using the milled compressor volute, the gas does not pass neither the mass flow meter nor the temperature and pressure probes downstream the compressor. Hence, none compressor map can be obtained for this experiments. When it has been tried to reach even higher rotational speeds during the expansion to the ambient pressure, the lubrication film has broken down. At this condition a huge amount of oil is sucked and blown to the surrounding and metal to metal contact occurs, which can result in the destruction of the turbocharger. This denotes a limitation of obtaining zero efficiency measurements of the turbine driven by the compressor for the test facility in the current setup of Figure 4 .

\subsubsection{Turbine side}

Via using the milled compressor volute the reduced speed of $4890 \mathrm{rpm} / \mathrm{K}^{0.5}$ has additionally been measured. The results are shown in Figure 13. Due to the blown compressor exhaust the experimental condition inside of the test bench has changed to higher outer air velocities and thus higher convective heat fluxes. Hence, the measurements at particular operating points have been repeated to prove the repeatability of those and a high repeatability has been stated. 


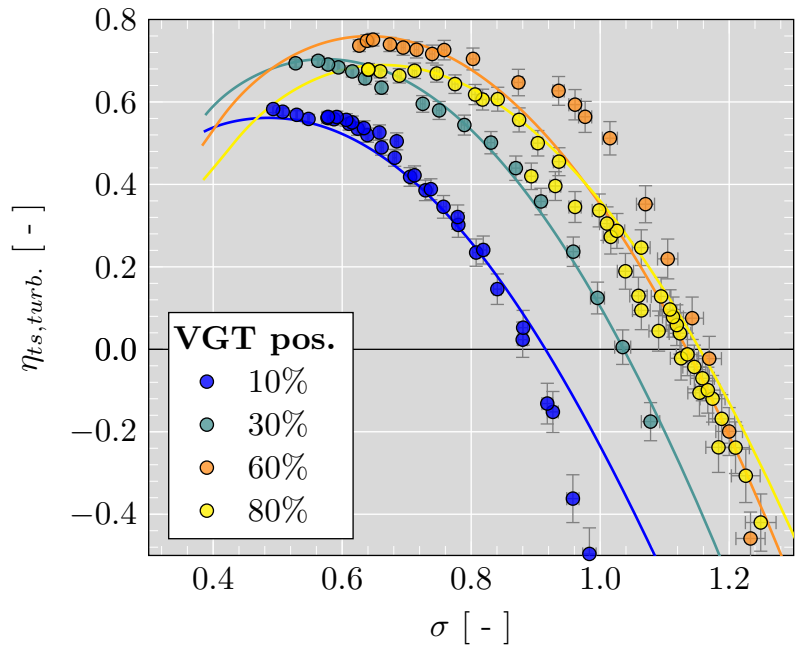

(a) Efficiency at $4890 \mathrm{rpm} / \mathrm{K}^{0.5}$

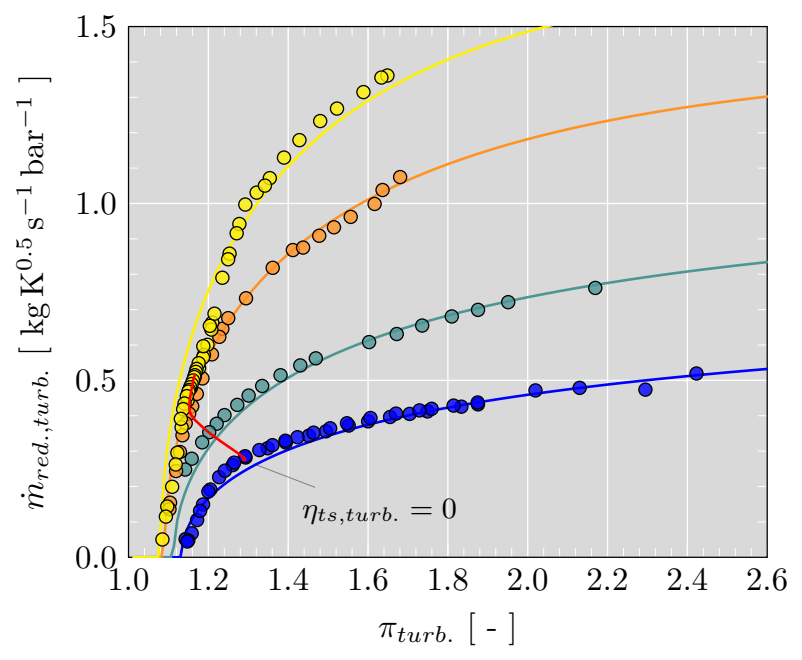

(b) $\dot{m}_{r e d .}$ at $4890 \mathrm{rpm} / \mathrm{K}^{0.5}$

Figure 13: Turbine maps with milled compressor casing

It is worth highlighting that especially for the VGT opening of $80 \%$ a strong agreement between experimental and calculated (extrapolated) efficiency has been obtained with the model described in Payri et al. $[2]$.

\subsection{Without compressor wheel}

To gain beneficial results for the two remaining speeds $5830 \mathrm{rpm} / \mathrm{K}^{0.5}$ and $6715 \mathrm{rpm} / \mathrm{K}^{0.5}$, the point close to zero mechanical efficiency has been measured $\left(\dot{W}_{\text {comp. }}=0\right)$. For this purpose the power output/input of the compressor has to become zero wherefore the compressor wheel and its casing have been detached. Due to balancing issues a metal cylinder has been replaced.

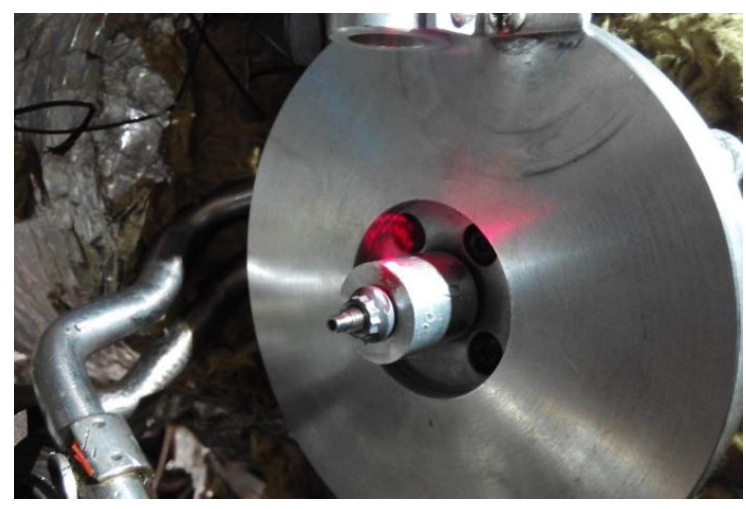

Figure 14: Metal cylinder which replaces the compressor wheel

Hence, the turbine has had to produce the power to overcome the friction losses in the bearings and also the friction losses of the metal cylinder with the surrounding air.

\subsubsection{Turbine side}

For the two higher rotational speeds the normal operating range has been measured by means of the original compressor volute. Additionally, the points of zero mechanical efficiency have been measured with the aforementioned assembly. The obtained results are presented in Figure 15(a) - Figure 15(d). 


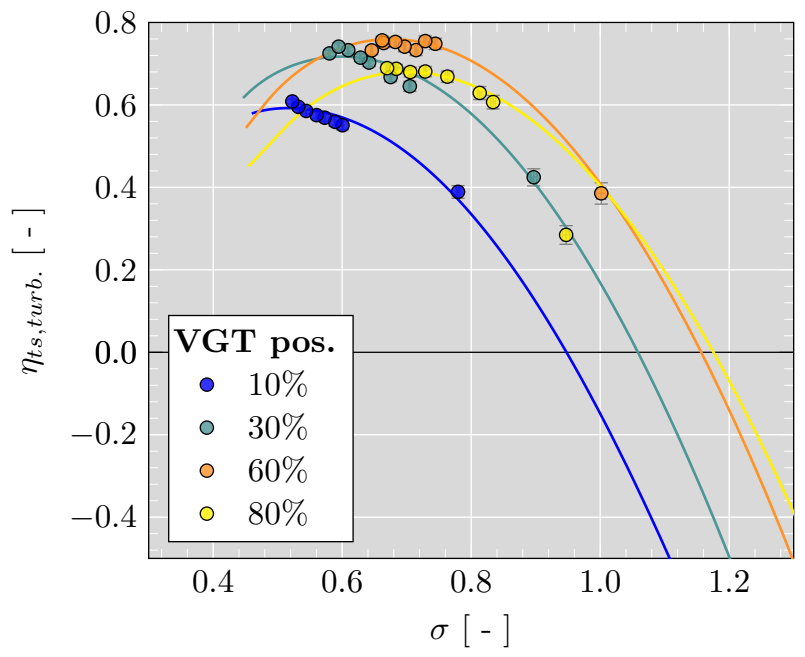

(a) Efficiency at $5830 \mathrm{rpm} / \mathrm{K}^{0.5}$

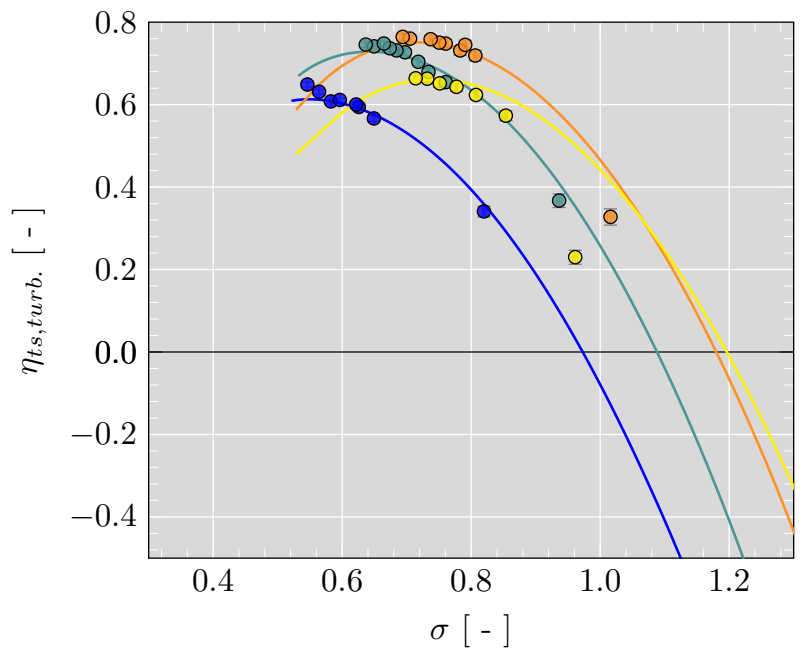

(c) Efficiency at $6715 \mathrm{rpm} / \mathrm{K}^{0.5}$

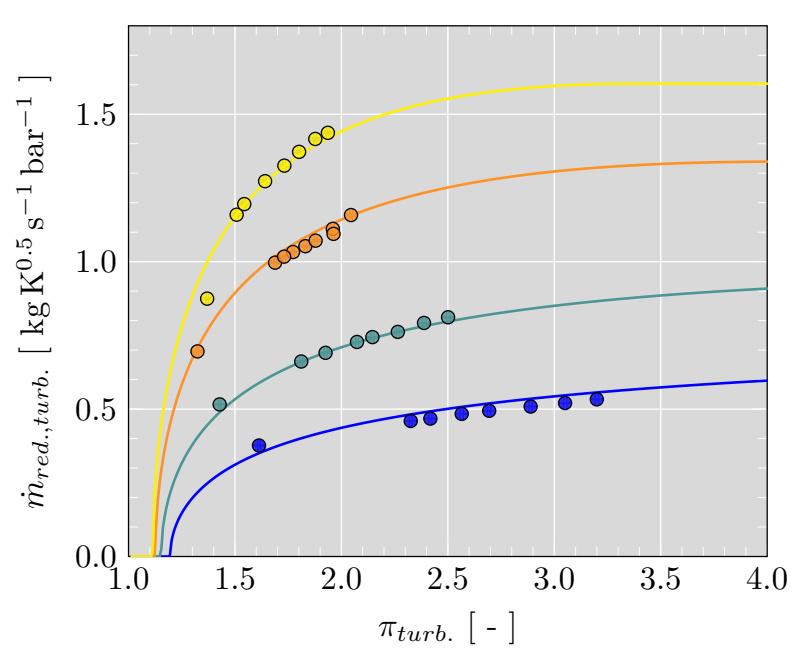

(b) $\dot{m}_{r e d .}$ at $5830 \mathrm{rpm} / \mathrm{K}^{0.5}$

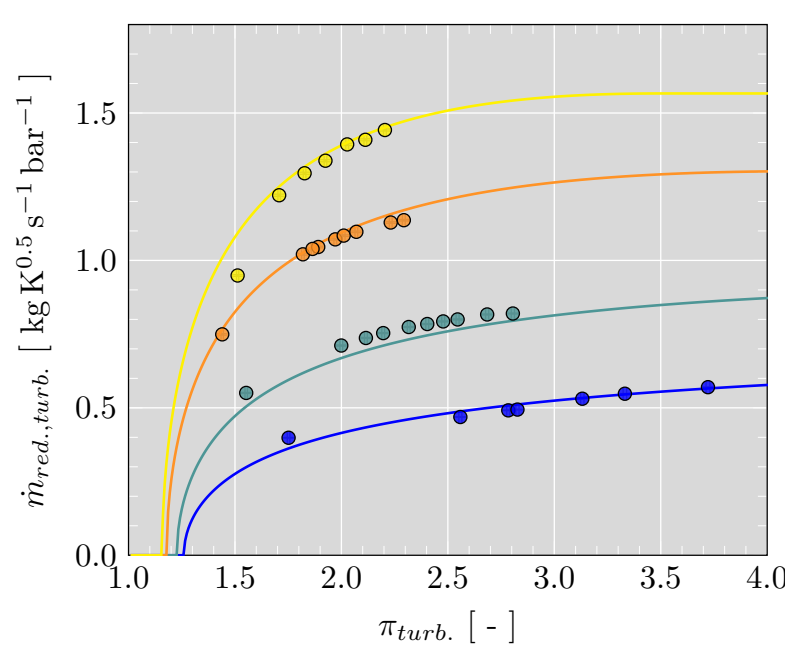

(d) $\dot{m}_{r e d}$ at $6715 \mathrm{rpm} / \mathrm{K}^{0.5}$

Figure 15: Turbine maps; stars obtained with cylinder on compressor side

In the case of the measurements for $80 \%$ VGT opening the points measured with zero compressor power show very bad agreement with extrapolated trends for the reduced speeds $5830 \mathrm{rpm} / \mathrm{K}^{0.5}$ and $6715 \mathrm{rpm} / \mathrm{K}^{0.5}$ (Figure 15). It is expected to have an error in the measurement according to VGT position or turbospeed since they are the only points with such a level of disagreement and the uncertainty is low at these reduced speeds.

\section{Uncertainty analysis \& future improvement discussion}

The uncertainties for the BSR and the efficiency are calculated as it is proposed in GUM [33]: 


$$
\begin{aligned}
u_{c}^{2}= & \sum_{i=1}^{n}\left\{\frac { 1 } { 2 } \left(f\left[x_{1}, \ldots, x_{i}+u\left(x_{i}\right), \ldots, x_{n}\right]\right.\right. \\
& \left.\left.-f\left[x_{1}, \ldots, x_{i}-u\left(x_{i}\right), \ldots, x_{n}\right]\right)\right\}^{2} .
\end{aligned}
$$

High inherent inaccuracies occur when measuring at low turbine power with low pressure ratio and are naturally increasing towards higher BSRs and towards lower reduced speeds like visible in Figure 16.

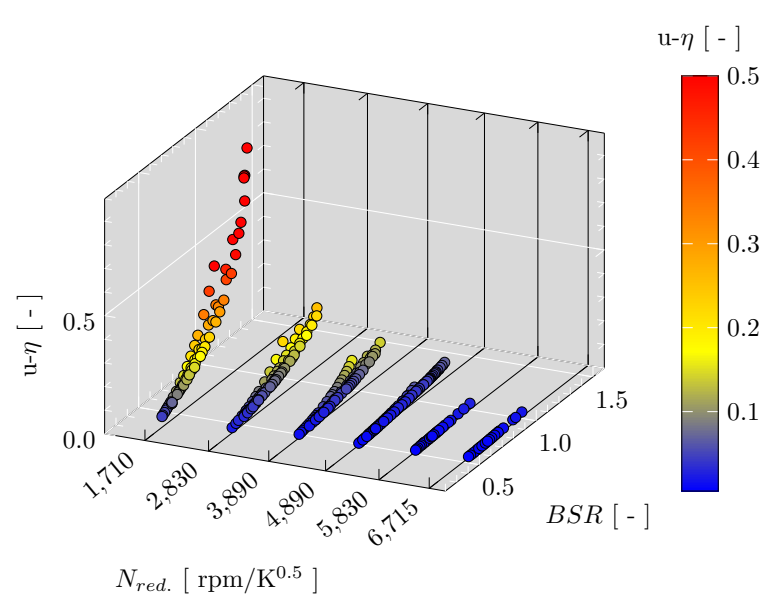

(a) Possible $\eta_{\text {turb. }}$-error

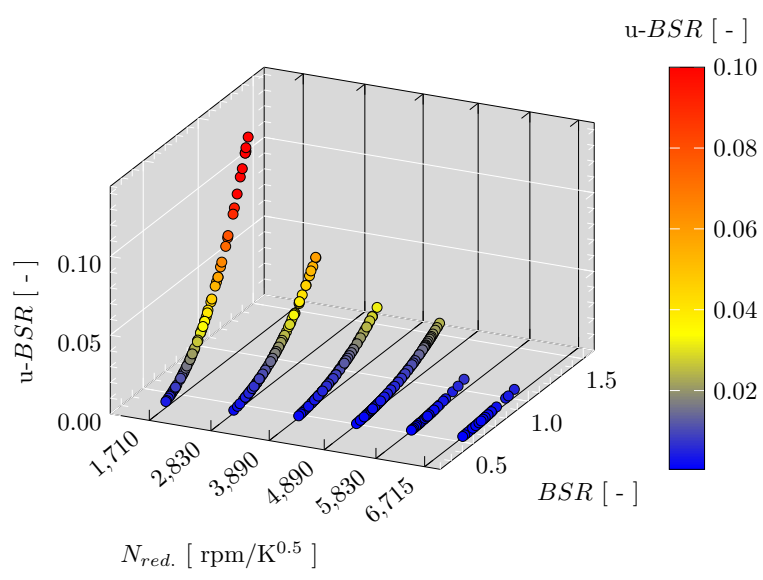

(b) Possible BSR-error

Figure 16: Measurement uncertainties

Consequently, measuring at higher rotational speeds for obtaining extreme off-design results allows to obtain a more trustworthy dataset. Thus, it is from interest to improve the measurement method and to allow measurements at higher speeds. The obtained mass flow maps in this paper are less influenced by the heat transfer, as observed by Serrano et al. [12], and thus, its measurement accuracies. Since these uncertainties are not worth mentioning they are not presented.

For an improvement of the measurement quality at the running points of extreme off-design and low reduced speeds advanced measurement methods like presented by Baar et al. [34] would be of high interest.

Apart from the presented three assemblies remaining possibilities do exist to control and to increase the power output of the compressor in order to obtain turbine measurements at low mass flows for higher compressor speeds. From Equation 2 and Equation 3 it is easily deduced that the inlet Temperature has a high impact on the compressor work. Thus, increasing the inlet temperature results in significantly higher compressor power outputs according to the model results in figure Figure 17. 


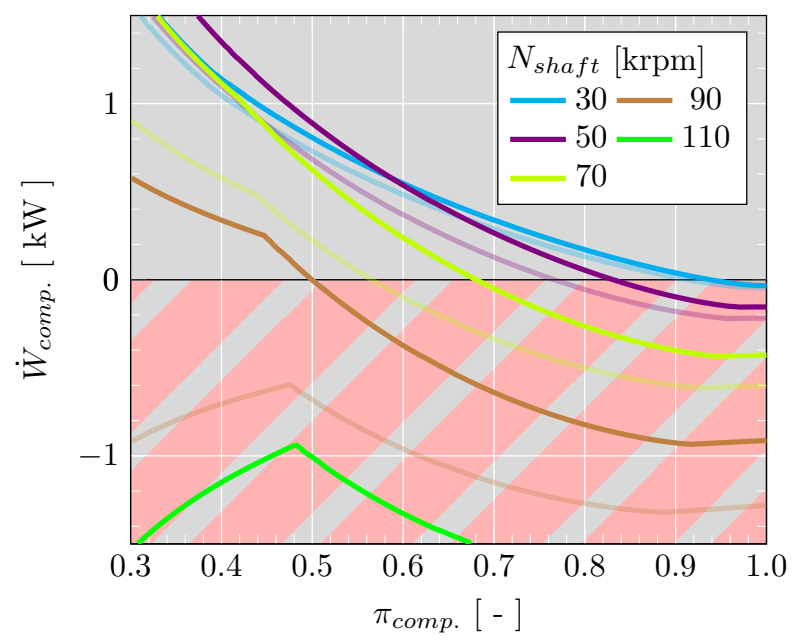

Figure 17: Compressor model results with $180^{\circ} \mathrm{C}$ inlet temperature and imposed swirl component $c_{\theta, 1}\left(\alpha_{1}=50^{\circ}\right)$; compared with results of Figure 7 (light color lines)

The inlet temperature and simultaneously the inlet pressure can be risen by increasing the power of the screw compressor, which has been limited by the maximum power of $150 \mathrm{~kW}$ of the reversible brake in the presented experiment. Also it has to be taken care, that the quasi-adiabatic test condition keeps valid. Furthermore, the limitation of the second assembly due to lubrication film failure could be overcome by reducing the oil pump pressure below ambient (e.g. 0.7 bar to 0.6 bar) conditions by means of a vacuum pump. Thus, loss of the oil can be controlled.

\section{Summary \& conclusion}

In this paper, a systematic procedure for measuring radial turbine performance at extreme high blade speed ratios and almost zero mass flow has been developed.

In the experiments, the turbocharger compressor acts not only as a braking unit but also as a power supplier for the turbine. To run the compressor as a centrifugal turbine several limitations like e.g. rotor choking and volute choking have had to be overcome due to modifications of the initial assembly.

First, an IGV has been introduced into the inlet duct of the compressor to produce a inlet momentum and to take advantage of Euler's turbomachinery equation for assisting and powering the turbocharger shaft. A comparison with a unmodified compressor has clarified the benefit of using inlet swirl for the conversion of the compressor into a centrifugal turbine. By means of this assembly turbine efficiencies much lower than zero percent, where the turbine even consumes power, have been measurable for three moderate reduced rotational speeds at almost adiabatic conditions. Since the compressor has worked close to choke when powering the turbocharger shaft, no higher speed has been measurable.

Second, by milling the compressor volute the air has been able to expand to the ambient pressure and thus, the compressor has been able to produce enough power to turn the turbocharger shaft at higher speed. At even higher speed the lubrication film has collapsed due to the low pressure at the compressor side. Consequently, four complete speedlines have been measured by means of the presented approaches. In normal hot conditions these result in the full range of turbocharger speeds, that is usually found during urban driving. Thus, valuable data for model development and evaluation have been obtained.

Third, for even higher speeds the compressor wheel has been replaced by a balanced cylinder. With this kind of assembly it has been possible to obtain the point of zero mechanical efficiency in a simple way and to gain additional data for very high speeds.

The uncertainties, which play an important role at low efficiency measurements, have been observed. The possible errors have a very high magnitude for low rotational speeds. Even though, a high repeatability has been stated for the tests. 


\section{Acknowledgements}

The authors of this paper wish to thank M.A. Ortiz for his invaluable help during the experimental setup. The work has been partially supported by the Spanish Ministry of Economy and Competitiveness through grant number TRA2013-40853-R.

\section{Nomenclature}

$\begin{array}{ll}B S R & \text { Blade speed ratio } \\ c & \text { velocity in absolute reference frame } \\ c_{p} & \text { Isobaric specific heat capacity } \\ c o m p & \text { Compressor } \\ I C S & \text { Independent Cooling System } \\ I L S & \text { Independent Lubrication System } \\ m e c h . & \text { Mechanical condition } \\ \dot{m} & \text { Mass flow } \\ N & \text { Rotational speed } \\ p & \text { Pressure } \\ \dot{Q} & \text { Heat flow } \\ R & \text { Radius } \\ r e d . & \text { Reduced numbers } \\ s & \text { Static conditions } \\ T & \text { Temperature } \\ t & \text { Total or stagnation conditions } \\ t u r b . & \text { Turbine } \\ u & \text { Uncertainty } \\ \dot{W} & \text { Power } \\ w & \text { velocity in relative reference frame } \\ 1 & \text { Compressor inlet section } \\ 2 & \text { Compressor outlet section } \\ 3 & \text { Turbine inlet section } \\ 4 & \text { Turbine outlet section }\end{array}$

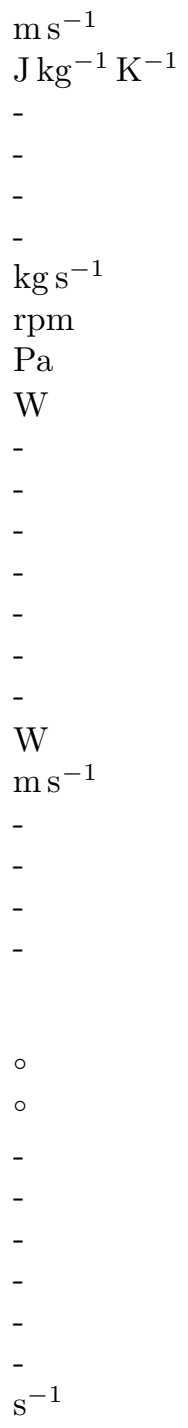

Greek letters

$\begin{array}{lll}\alpha & \text { Angle in absolute reference frame } & \circ \\ \beta & \text { Angle in relative reference frame } & \circ \\ \gamma & \text { Heat capacity ratio } & - \\ \Delta & \text { Difference } & - \\ \eta & \text { Efficiency } & - \\ \theta & \text { Circumferential components } & - \\ \pi & \text { Corresponding pressure ratio } & - \\ \sigma & \text { Blade speed ratio } & - \\ \omega & \text { Angular velocity } & \mathrm{s}^{-1} \\ \text { Overbar } & \end{array}$

[1] European Parliament, Council of the European Union, . Regulation (EC) No 715/2007 of the European Parliament and of the Council of 20 June 2007 on type approval of motor vehicles with respect to emissions from light passenger and commercial vehicles (Euro 5 and Euro 6) and on access to vehicle repair and maintenance information (Text with EEA relevance) . Official Journal of the European Union 2007;50:1-16. URL: http://eur-lex.europa.eu/legal-content/EN/ TXT/?uri=0J:L: $2007: 171:$ TOC. 
[2] Payri, F., Serrano, J.R., Fajardo, P., Reyes-Belmonte, M.A., Gozalbo-Belles, R.. A physically based methodology to extrapolate performance maps of radial turbines. Energy Conversion and Management 2012;55(0):149 - 163. doi:10. 1016/j .enconman. 2011.11.003.

[3] Romagnoli, A., Martinez-Botas, R.. Performance prediction of a nozzled and nozzleless mixed-flow turbine in steady conditions. International Journal of Mechanical Sciences 2011;53(8):557 - 574. doi:10.1016/j.ijmecsci.2011.05.003.

[4] Zhu, S., Deng, K., Liu, S.. Modeling and extrapolating mass flow characteristics of a radial turbocharger turbine. Energy 2015;87:628-637. doi:10.1016/j.energy.2015.05.032.

[5] Rajoo, S., Romagnoli, A., Martínez-Botas, R.F.. Unsteady performance analysis of a twin-entry variable geometry turbocharger turbine. Energy 2012;38:176-189. doi:10.1016/j.energy.2011.12.017.

[6] Chiong, M.S., Rajoo, S., Martínez-Botas, R.F., Costall, A.. Engine turbocharger performance prediction: Onedimensional modeling of a twin entry turbine. Energy Conversion and Management 2012;57:68-78. doi:10.1016/j . enconman.2011.12.001.

[7] Galindo, J., Tiseira, A., Fajardo, P., García-Cuevas, L.M.. Development and validation of a radial variable geometry turbine model for transient pulsating flow applications. Energy Conversion and Management 2014;85(0):190 - 203. doi:10. 1016/j.enconman.2014.05.072.

[8] Broatch, A., Serrano, J., Arnau, F., Moya, D.. Time-domain computation of muffler frequency response: Comparison of different numerical schemes. Journal of Sound and Vibration 2007;305(12):333 - 347. URL: http://www.sciencedirect. com/science/article/pii/S0022460X07002799. doi:http://dx.doi.org/10.1016/j.jsv.2007.04.023.

[9] Galindo, J., Serrano, J., Arnau, F., Piqueras, P.. Description of a Semi-Independent Time Discretization Methodology for a One-Dimensional Gas Dynamics Model. Journal of Engineering for Gas Turbines and Power 2009;131. doi:10.1115/ 1.2983015.

[10] Galindo, J., Climent, H., Tiseira, A., García-Cuevas, L.M.. Effect of the numerical scheme resolution on quasi-2d simulation of an automotive radial turbine under highly pulsating flow. Journal of Computational and Applied Mathematics 2016;291:112-126. doi:10.1016/j.cam.2015.02.025.

[11] Galindo, J., Luján, J., Serrano, J., Dolz, V., Guilain, S.. Design of an exhaust manifold to improve transient performance of a high-speed turbocharged diesel engine. Experimental Thermal and Fluid Science 2004;28(8):863 - 875. doi:10.1016/j.expthermflusci.2004.01.003

[12] Serrano, J.R., Olmeda, P., Arnau, F.J., Dombrovsky, A., Smith, L.. Analysis and methodology to characterize heat transfer phenomena in automotive turbochargers. Journal of Engineering for Gas Turbines and Power 2015;137:021901-1 - 021901-11. doi:10.1115/1.4028261.

[13] Serrano, J.R., Olmeda, P., Páez, A., Vidal, F.. An experimental procedure to determine heat transfer properties of turbochargers. Measurement Science and Technology 2010;21(3):035109. doi:10.1088/0957-0233/21/3/035109.

[14] Payri, F., Olmeda, P., Arnau, F.J., Dombrovsky, A., Smith, L.. External heat losses in small turbochargers: Model and experiments. Energy 2014;71:534546. doi:10.1016/j.energy.2014.04.096.

[15] Serrano, J.R., Olmeda, P., Arnau, F.J., Dombrovsky, A.. General procedure for the determination of heat transfer properties in small automotive turbochargers. SAE Int J Engines 2014;8(1). doi:10.4271/2014-01-2857.

[16] Serrano, J.R., Olmeda, P., Arnau, F.J., Dombrovsky, A., Smith, L.. Turbocharger heat transfer and mechanical losses influence in predicting engines performance by using one-dimensional simulation codes. Energy 2015;86:204218. doi:10.1016/j.energy.2015.03.130.

[17] Serrano, J., Arnau, F., Dolz, V., Piqueras, P.. Methodology for characterisation and simulation of turbocharged diesel engines combustion during transient operation. part 1: Data acquisition and post-processing. Applied Thermal Engineering 2009;29(1):142 - 149. URL: http://www.sciencedirect.com/science/article/pii/S135943110800077X. doi:http://dx. doi.org/10.1016/j.applthermaleng.2008.02.011.

[18] Bellis, V.D., Bozza, F., Schernus, C., Uhlmann, T.. Advanced numerical and experimental technique for the extension of turbine mapping. SAE int J Engines 2013;3(6):1771-1785. doi:10.4271/2013-24-0119.

[19] Smiljanovski, V., Schorn, N., Scharf, J., Funken, B., Pischinger, S.. Messung des turbinenwirkungsgrades bei niedrigen turboladerdrehzahlen. Aufladetechnische Konferenz 2008;

[20] Deligant, M., Podevin, P., Descombes, G.. Experimental identification of turbocharger mechanical friction losses. Energy 2012;39(1):388-394. doi:10.1016/j.energy.2011.12.049.

[21] Terdich, N.. Impact of electrically assisted turbocharging on the transient response of an off-highway diesel engine. Ph.D. thesis; Imperial College London; 2015.

[22] Salameh, G., Chesse, P., Chalet, D.. Different measurement techniques for wider small radial performance maps. Experimental Techniques 2016;40(6):1511-1525. doi:10.1007/s40799-016-0107-8.

[23] Pucher, A.. Overall engine process simulation - an important tool for the development of supercharged engines. International Conference on Turbochargers and Turbocharging 2002;C602(045):155-166.

[24] Leufvén, O., Eriksson, L.. Measurements, analysis and modeling of centrifugal compressor flow for low pressure ratios. International Journal of Engine Research 2013;doi:10.1177/1468087414562456.

[25] Wallace, F.J., Whitfield, A., Atley, R.C.. Experimental and theoretical performance of radial flow turbocharger compressor with inlet prewhirl. Proceedings of the Institution of Mechanical Engineering 1975;189(43/75):177-186. doi:10. 1243/PIME_PROC_1975_189_024_02.

[26] Najjar, Y.S.H., Akeel, S.A.M.S.. Effect of prewhirl on performance of centrifugal compressors. International Journal of Rotating Machinery 2002;8(6):397-401. doi:10.1080/10236210214326.

[27] Müller, M., Sumser, S., Fledersbacher, P., Rößler, K., Fieweger, K., Bauer, H.J.. Using the centrifugal compressor as a cold air turbine. In: editor, T., editor. 8th International Conference on Turbochargers and Turbocharging; vol. 8. Institution of Mechanical Engineers Combustion Engines \& Fuels Group; Woodhead Publishing in Mechanical Engineering; 
2006, p. 55-67.

[28] Galindo, J., Serrano, J.R., Guardiola, C., Cervelló, C.. Surge limit definition in a specific test bench for the characterization of automotive turbochargers. Experimental Thermal and Fluid Science 2006;30(5). doi:10.1016/j.expthermflusci. 2005.06 .002 .

[29] Futral, S., Wasserbauer, C., Aeronautics, U.S.N., Administration, S.. Off-design performance prediction with experimental verification for a radial-inflow turbine: Samuel m.futral jr. and charles a. wasserbauer. Tech. Rep. NASA TN D-2621; NASA; 1965. URL: http://books.google.es/books?id=N1kzLAHfK-IC.

[30] Inc., M.. Field experiences with vcone ${ }^{\circledR}$ technology. Tech. Rep.; McCrometer Inc. Hemet, CA.; 2008.

[31] Jacobs, E.N., Ward, K.E., Pinkerton, R.M.. The characteristics of 78 related airfoils sections from tests in the variabledensity wind tunnel. Tech. Rep.; National Advisory Committee for Aeronautics; 1933.

[32] Serrano, J.R., Arnau, F.J., García-Cuevas, L.M., Dombrovsky, A., Tartousi, H.. Development and validation of a radial turbine efficiency model at extreme off-design conditions. Energy Conversion and Management 2016;doi:10.1016/ j.enconman.2016.09.032.

[33] Evaluation of measurement data - Guide to the expression of uncertainty in measurement; 2008. URL: http://www.bipm. org/utils/common/documents/jcgm/JCGM_100_2008_E.pdf.

[34] Baar, R., Biet, C., Boxberger, V., Mai, H., Zimmermann, R.. New evaluation of turbocharger components based on turbine outlet temperature measurements in adiabatic conditions. International Symposium on Transport Phenomena and Dynamics of Rotating Machinery 2014;15. 